\title{
Vapor Pressures of the Methanes ${ }^{1}$
}

\author{
George T. Armstrong, F. G. Brickwedde, and R. B. Scott
}

\begin{abstract}
Experimental measurements, not previously reported in detail, of the vapor pressure of $\mathrm{CH}_{4}$ and the differences in vapor pressures of $\mathrm{CH}_{4}$ and the deuteromethanes below the normal boiling point are presented. A critical review of the literature relating to the vapor pressures of methane and the deuteromethanes is given. On the basis of the experimental measurements and the previous literature the following best values are assigned to fixed points on the vapor pressure curves. The triple points are: $\mathrm{CH}_{4}, 87.50 \mathrm{~mm}, 90.66^{\circ} ; \mathrm{CH}_{3} \mathrm{D}, 84.5 \mathrm{~mm}$, $90.41^{\circ} ; \mathrm{CH}_{2} \mathrm{D}_{2}, 82.0 \mathrm{~mm}, 90.17^{\circ} ; \mathrm{CHD}_{3}, 80.2 \mathrm{~mm} .89 .96^{\circ} ; \mathrm{CD}_{4}, 79.1 \mathrm{~mm}, 89.79^{\circ} \mathrm{K}$. The boiling point of $\mathrm{CH}_{4}$ is $111.67^{\circ} \mathrm{K}$; the critical point 45.6 atmospheres and $190.6^{\circ} \mathrm{K}$. Equations and a table are given for the vapor pressure of $\mathrm{CH}_{4}$ in the solid region, the liquid region below the normal boiling point and the liquid region above the normal boiling point.

The ratios of the vapor pressures of the methanes are expressed by equations of the form $T \log _{10} P_{\mathrm{D}} / P_{\mathrm{H}}=A-B / T$. The constants $A$ and $B$ have the following values, respectively: in the solid range $\mathrm{CH}_{3} \mathrm{D}, 1.260,110.2 ; \mathrm{CH}_{2} \mathrm{D}_{2}, 2.694,222.2 ; \mathrm{CHD}_{3}, 4.452,351.7$; $\mathrm{CD}_{4}, 5.529,410.5$; in the liquid range, $\mathrm{CH}_{3} \mathrm{D}, 1.328,129.5 ; \mathrm{CH}_{2} \mathrm{D}_{2}, 2.671,245.4 ; \mathrm{CHD}_{3}$, $3.969,343.8 ; \mathrm{CD}_{4}, 5.159,421.1$. The vapor-pressure ratios of the isotopic methanes form a nearly geometric progression with increasing deuterium substitution. Deviations of their mixtures from ideal solutions are very small.
\end{abstract}

\section{A Review of the Vapor Pressure of Meth- ane and the Deuteromethanes}

\subsection{Methane}

The vapor pressure of solid and liquid methane has been determined in various temperature ranges by many investigators, and, in addition, there have been several summaries of the published data. S. F. Pickering [1] ${ }^{2}$ reviewed the literature relating to the critical constants; Copson and Frolich [2] summarized the vapor-pressure data available in 1929; and Stull summarized the data in 1950 [3]. A series of best values appeared in the International Critical Tables [4]; Egloff [5] and Timmermans [6] surveyed the literature in preparation for their reference books of physical constants of hydrocarbons; and a table of selected values for the vapor pressure below the normal boiling point was given by Rossini and coworkers in collaboration with the American Petroleum Institute [7]. Other, less critical, surveys have also been made. An important deficiency remaining after the above summaries is that the excellent API table of vapor pressures in the low-pressure range is based to a considerable extent on data not generally available.

In an attempt to remedy this deficiency this review has been prepared in which the data from various sources have been compared including those described in section 2, previously unpublished, and available to none of the previous reviewers except perhaps Rossini. An attempt has been made to find equations which fit well the best available data and at the same time pass through selected best values for the triple point, normal boiling point, and critical point.

\footnotetext{
1 This research was supported in part by the ${ }^{-}$Atomic Energy Commission.

${ }^{2}$ Figures in brackets indicate the literature references at the end of this paper.
}

The vapor pressure of solid methane has been measured by Hunter [8], Henning and Stock [9], Karwat [10], Freeth and Verschoyle [11], Tichner and Lossing [12] and by Brickwedde and Scott of the National Bureau of Standards (section 2 of this paper). Determinations of the triple point as listed in table 1 provide a fixed point through which an equation for the data should pass. Of the reported determinations, the extensive data from Clusius' laboratory appear to be best represented by the values $90.67 \pm 0.03^{\circ} \mathrm{K}$ and $87.4 \pm 0.1 \mathrm{~mm}$, which were determined from a study of the melting temperature as a function of pressure. The values $90.660 \pm 0.005^{\circ} \mathrm{K}$ and $87.60 \pm 0.10 \mathrm{~mm}$. were found by Brickwedde and Scott with a carefully purified sample. The best values of the triple point temperature and pressure appear to be $90.66 \pm 0.01^{\circ} \mathrm{K}$ and $87.50 \pm 0.10 \mathrm{~mm}$.

TABLE 1. Triple point of methane

\begin{tabular}{|c|c|c|c|}
\hline Observer & Date & Temperature & Pressure \\
\hline $\begin{array}{l}\text { Olszewski [13] } \\
\text { Hunter [8] } \\
\text { Crommelin [14] } \\
\text { Henning and Stock [9] } \\
\text { Eucken and Karwat [15] } \\
\text { Clusius [16] } \\
\text { Wiebe and Brevoort [17] } \\
\text { Freeth and Verschoyle [11] } \\
\text { Fischer and Klemm [18] } \\
\text { Kruis, Popp, and Clusius [19] } \\
\text { Clusius, Popp, and Frank [20] } \\
\text { Frank and Clusius [21] } \\
\text { Brickwedde and Scott (this re- } \\
\text { port) } \\
\text { Clusius and Wiegand [22] } \\
\text { Stavely and Gupta [23] } \\
\quad \text { Selected values }\end{array}$ & $\begin{array}{l}1885 \\
1906 \\
1912 \\
1921 \\
1924 \\
1929 \\
1930 \\
1931 \\
1935 \\
1937 \\
1937 \\
1937 \\
1937 \\
1940 \\
1949 \\
-\end{array}$ & $\begin{array}{l}\quad{ }^{\circ} K \\
87.4 \\
90.5 \text { to } 91.2 \\
90.01 \\
89.9 \\
\text { a } 90.6 \\
90.6 \\
90.3 \\
90.70 \\
90.7 \\
90.6 \\
90.62 \\
90.6 \\
90.660 \pm 0.005 \\
90.67 \pm 0.03 \\
90.66\end{array}$ & $\begin{array}{l}\quad m m \mathrm{Hg} \\
80 \\
92 \\
70 \\
78.3 \\
87.3 \\
\\
\text { b } 87.52 \pm 0.15 \\
83.85 \\
87.5 \\
87.5 \\
87.4 \pm 0.05 \\
87.60 \pm 0.10 \\
87.4 \pm 0.1 \\
87.75 \pm 0.07 \\
87.50\end{array}$ \\
\hline
\end{tabular}

a Corrected by $0.1^{\circ} \mathrm{K}$ for change of temperature scale.

b A verage of two values. 
Of the various equations that have been proposed the Antoine type equation given by Rossini et al., appears to give the most satisfactory fit to the data from various sources.

This equation presents a compromise between the NBS data and those of Freeth and Verschoyle and of Karwat in the region from $80^{\circ} \mathrm{K}$ to the triple point, at which point it represents a good average of the pressures found by Brickwedde and Scott and by Clusius and Wiegand. The equation is in excellent agreement with the recent smoothed data of Tichner and Lossing down to $0.01 \mathrm{~mm}$. Below this it deviates by as much as 10 percent from their data.

When eq (1a) given by Rossini

$$
\log _{10} P(\mathrm{~mm})=7.69540-532.20 /(T+1.84)
$$

is solved simultaneously with eq (2) for the liquid state vapor pressure, these two equations give values of $90.67^{\circ} \mathrm{K}$ and $87.7 \mathrm{~mm}$ for the triple point temperature and pressure. In the original equations by Rossini temperature is given in degrees $\mathrm{C}$ and for the conversion to absolute temperature $(T)$ the ice point is taken as $273.16^{\circ} \mathrm{K}$. As the value of the pressure is higher than the reported values in general, a very small adjustment was made in the equation for the solid state vapor pressure to bring the triple point pressure to $87.50 \mathrm{~mm}$. The corresponding temperature is $90.66^{\circ}$ in agreement with the value selected above. The revised equation for the vapor pressure of solid methane is

$$
\log _{10} P(\mathrm{~mm})=7.69540-532.20 /(T+1.842) .
$$

The adjustment is so slight that it changes the value of $P$ at any given temperature by a maximum of $0.02 \mathrm{~mm}$, which is well within the limits of error of most of the data. Besides the achievement of consistency at the triple point of $\mathrm{CH}_{4}$ this adjustment appears also to be justified by a greater consistency in the vapor pressures of the deuteromethanes at their triple points, as is shown later. The individual vapor pressure measurements of various investigators have been compared with eq (1b) and the deviations are plotted in figure 1 .

The vapor pressure of liquid methane in the range below its normal boiling point has been represented in the published literature (for example: references $[4,24,25])$ most frequently by tables based on the relatively few reported measurements of Henning and Stock [9]. Data of Keyes, Taylor, and Smith [26] lying 1 or 2 percent higher, but of equally good internal consistency in this region, have generally been disregarded. Besides these two sources of data there are some early measurements of Hunter [8] which appear to be of low accuracy. A few values were obtained by Cragoe [27] in this region but were never published. To these may be added the data described in section 2, which are of high internal precision and cover the range more thoroughly than previous studies. Equation (2) published by Rossini et al., appears to be based largely on the latter data.

$$
\log _{10} P(\mathrm{~mm})=6.61184-389.93 /(T-7.16) .
$$
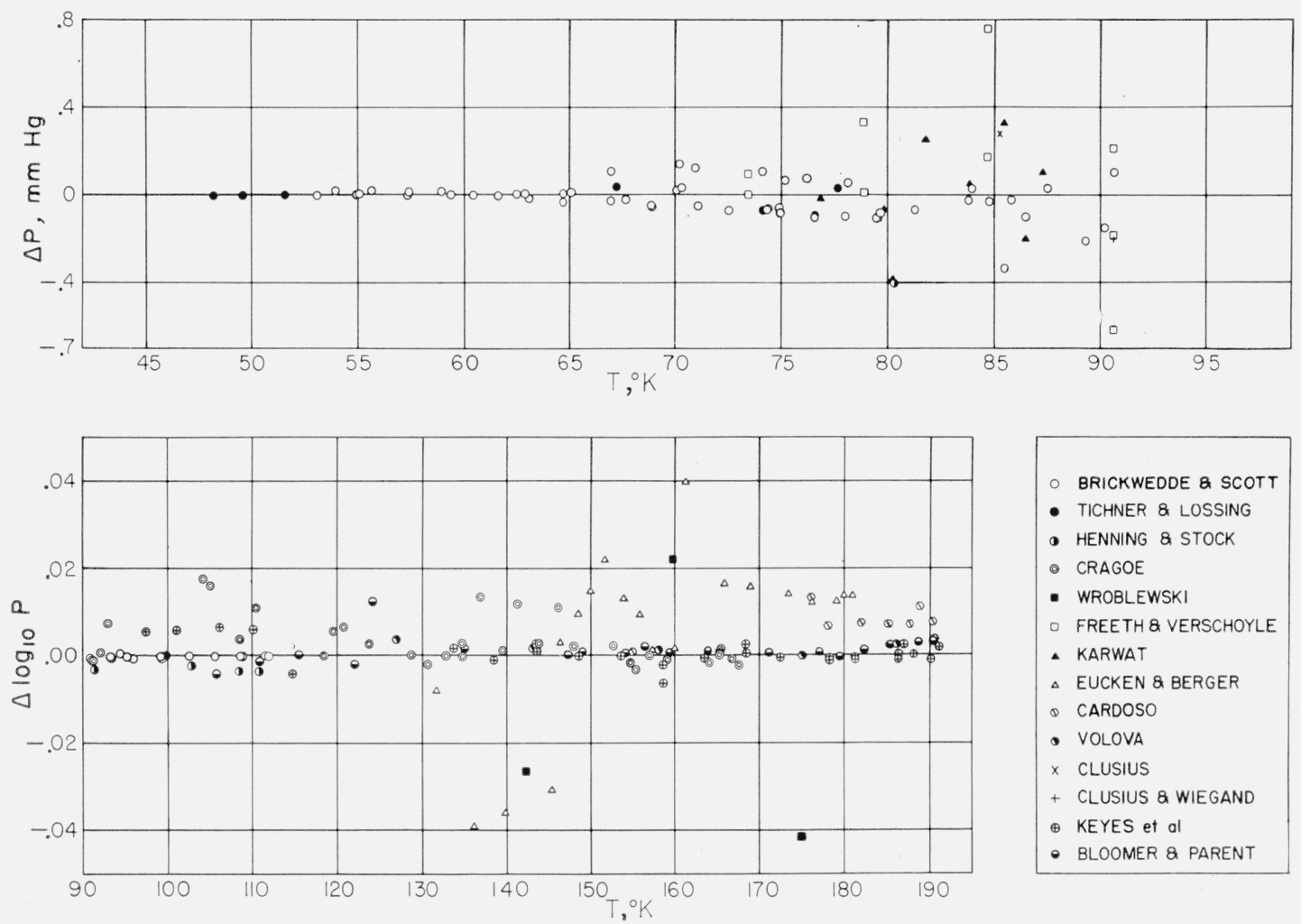

Figure 1. Deviations (obs-calc) of the experimental data from table 4. 
The normal boiling point calculated from this equation is $111.67^{\circ} \mathrm{K}$. Because this value is only $0.001^{\circ}$ from the value found by Brickwedde and Scott and within $0.01^{\circ}$ of the mean of the values reported by Henning and Stock, by Cragoe, and by Keyes, Taylor, and Smith, it appears to be the best value, with an estimated uncertainty of $\pm 0.01^{\circ} \mathrm{K}$. The uncertainties listed here and later are estimates of the limits within which the true value has a 50 percent probability of lying. Observed values are shown for comparison in table 2. The deviations of the measured data from eq (2) are shown in figure 1. It will be seen that the equation agrees closely with the data of Brickwedde and Scott and lies near that of Henning and Stock at the center of the range. It may be noted here that in addition to eq (1) and (2) other equations of different functional form can be made to fit the data with nearly as great precision, as for instance those given in section 2 .

TAвLE 2. Normal boiling point of methane

\begin{tabular}{|c|c|c|}
\hline Observer & Date & Temperature \\
\hline $\begin{array}{l}\text { Olszewski [13] } \\
\text { Hunter [8] } \\
\text { Henning and Stock [9] } \\
\text { Keyes, Taylor, and Smith [26]. } \\
\text { C. S. Cragoe [27] } \\
\text { Brickwedde and Scott (section 2) } \\
\quad \text { Selected value }\end{array}$ & $\begin{array}{l}1885 \\
1906 \\
1921 \\
1922 \\
1919 \\
1937\end{array}$ & $\begin{array}{l}109.2^{\circ} K \\
110.2 \\
111.79 \\
111.55 \\
111.58 \\
111.669 \pm 0.010 \\
111.67 \pm 0.01\end{array}$ \\
\hline
\end{tabular}

In the pressure region above one atmosphere there are extensive but widely divergent data. Certain very early data such as those of Wroblewski [28] and of Olszewski [13] may be disregarded as lacking sufficient precision when compared with later data. There remain the data of Cardoso [29], Cragoe [27], Keyes, Taylor, and Smith [26], Eucken and Berger [30], Volova [31], and Bloomer and Parent [32]. These also differ widely among themselves. The paper of Eucken and Berger, for example, does not include any description of apparatus or technique and is reported in such a way as to leave the impression that the data are of only moderate accuracy. The scatter of the points is quite bad particularly at the lower temperatures. The data of Cardoso covering a limited temperature range are of a precision comparable with that of Keyes and of Cragoe, but differ from theirs by about 2 percent. Keyes and coworkers suggested that an error of $0.56^{\circ}$ in Cardoso's temperature scale would account for the discrepancy, but as was pointed out by Pickering the line of argument leads to a temperature change, which if properly applied, widens the error instead of closing it.

The correction suggested by Keyes involved the use by Cardoso of the melting point of toluene as a calibration point for his thermometers, and a change in the accepted value of the melting point which occurred after Cardoso's measurements were published. Cardoso used $-94.5^{\circ} \mathrm{C}$ for this temperature. The thermometers used by Keyes were also used to measure the melting point of toluene [33], $-95.7^{\circ} \mathrm{C}$ being found. It might be pointed out that if this argument were extended to the present and the best value accepted for the melting point of toluene, $-94.991^{\circ} \mathrm{C}$ as found by Rossini et al. [21], then it appears (if the purity of the toluene and the technique of determining melting points are assumed to be sufficiently good in the early investigations) that the true temperature scale must be somewhere between that used by Cardoso and that used by Keyes. The assumption concerning the purity of the toluene is of doubtful validity. Assuming it to be true for the purpose of discussion, Cardoso's pressure measurements belong to lower true temperatures than he recorded. This results in raising the vapor pressure values for a particular true temperature. Similarly, Keyes' pressure measurements belong to higher true temperatures than he recorded, or the vapor pressure for a particular true temperature should be lower. This would widen the gap existing between the data by an amount corresponding to $1.2^{\circ}$ at the critical point. Adding this to the existing difference of about $0.5^{\circ}$, the difference in the data come to about $1.7^{\circ} \mathrm{C}$ near the critical point, or for a given temperature to about 5 percent in pressure. Examination of the several melting points recorded by Keyes and coworkers [33] suggests the possibility of a consistent error of $0.6^{\circ}$ to $0.8^{\circ}$ in his temperature scale in the region from $-112^{\circ}$ to $-95^{\circ} \mathrm{C}$.

The observed critical point pressure should be independent of temperature scales. Here we find that Cardoso measured a value $0.46 \mathrm{~atm}$. lower than that of Keyes. The difference can be due either to a difference in the purity of the $\mathrm{CH}_{4}$ used, or to calibration errors in the pressure scale. In this respect the calibrated steel tape used by Keyes for measurement of mercury column height seems definitely superior to the gas volume technique used by Cardoso.

In addition to the published data for methane, some vapor pressure measurements were made by Cragoe [27] in 1919, which were never published. These show an undesirable amount of scatter, but in general tend to fit the data of Keyes, Taylor, and Smith. Cragoe also tabulated values above $1 \mathrm{~atm}$. for the International Critical Tables which are based primarily on his own data and that of Keyes.

Volova [31] in a study of phase equilibria in methane-ethylene mixtures reported values for the vapor pressure of $\mathrm{CH}_{4}$ for which he claimed an accuracy of $0.2^{\circ}$ in temperature. The values for pressure which he gives lie within this limit of eq (3) and much closer to the data of Keyes and of Cragoe than to any other data.

TABLE 3. Critical point of methane

\begin{tabular}{|c|c|c|c|}
\hline Observer & Date & Temperature & Pressure \\
\hline $\begin{array}{l}\text { Dewar [34] } \\
\text { Wroblewski [28] } \\
\text { Olszewski [13] } \\
\text { Cardoso [29] } \\
\text { Keyes, Taylor, and Smith [26] } \\
\text { Bennewitz and Andreev [35] } \\
\text { Bloomer and Parent [32] } \\
\quad \text { Selected values }\end{array}$ & $\begin{array}{l}1884 \\
1884 \\
1885 \\
1915 \\
1922 \\
1929 \\
1952\end{array}$ & $\begin{array}{l}\circ K \\
173.7 \\
199.7 \\
191.4 \\
190.31 \\
191.06 \\
190.7 \\
190.55 \\
190.6\end{array}$ & $\begin{array}{l}\text { atm } \\
47.6 \\
56.8 \\
54.9 \\
45.60 \\
46.06 \\
45.7 \\
45.47 \\
45.6\end{array}$ \\
\hline
\end{tabular}


TABLE 4. Vapor pressure of methane

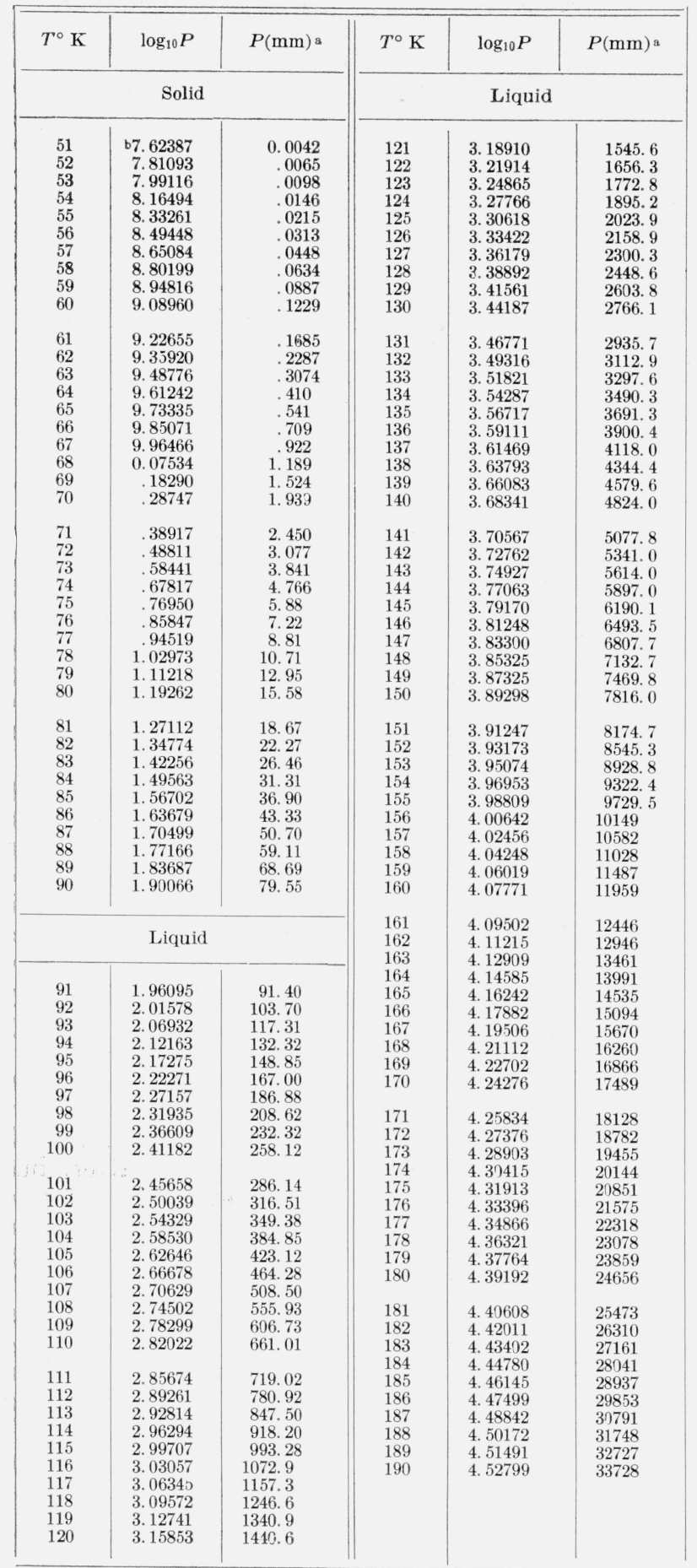

a The final figures in the values of $P(\mathrm{~mm})$ in general are not significant. b Logarithms have been increased by 10 where necessary to avoid negative characteristics.

The very recent work of Bloomer and Parent [32] provides good confirmation of the data of Keyes in the region between the boiling point and about $180^{\circ}$ $K$. Above that it tends to confirm the suggestion that the true temperatures lie somewhere between those of Keyes and Cardoso. Because it was received after the selection of the values listed in table 4 , it did not receive any weight in the establishment of these values, though it appears to offer a distinct improvement in the high pressure region. As was noted by Timmermans the critical constants of methane have been extremely uncertain considering the importance of this substance. The values $190.6^{\circ}$ $\mathrm{K}$ and $45.2 \mathrm{~atm}$ satisfy eq (3). However, a better value for the pressure on the basis of recent measurements would be $45.6 \mathrm{~atm}$. Table 3 lists measured values of the critical pressure and temperature for comparison. For purposes of interpolation the vapor pressure equation of Keyes' is unsatisfactory in that it does not join well with the recent low pressure data. Correction terms were added to the Keyes equation which bring the equation close to the values for pressure given in the International Critical Tables, and at the same time cause the equation to pass through the normal boiling point, $111.67^{\circ}$. Equation (3), derived in this way, was used as a basis for calculating deviations of experimental data plotted in figure 1 in the range above $111.67^{\circ}$.

$\begin{aligned} \log _{10} P(\mathrm{~mm}) & =10.68631-595.546 / T-0.0348066 \mathrm{~T} \\ & +0.00013338 T^{2}-1.7869 \times 10^{-7} T^{3}\end{aligned}$

Errors larger than 1 percent are unlikely in view of the values reported by Volova, by Cragoe, and by Bloomer and Parent.

As a summary of the vapor pressure of $\mathrm{CH}_{4}$, values have been calculated at selected temperatures with the use of eq (1b), (2), or (3) as appropriate, and these values are shown in table 4 .

\subsection{Deuteromethanes}

Aside from the studies made by Brickwedde and Scott at the Bureau, which have been briefly reported in a preliminary form [36] and which are described in detail in section 2 , the vapor pressure data on the deuteromethanes are rather sparse. A boiling point determination by Stedman [37] on a mixture of $\mathrm{CH}_{4}$ and $\mathrm{CH}_{3} \mathrm{D}$ indicated that the vapor pressure of $\mathrm{CH}_{3} \mathrm{D}$ is higher and that it might boil $0.5^{\circ}$ lower than $\mathrm{CH}_{4}$. A number of measurements were made of the triple point temperature and pressure of $\mathrm{CH}_{3} \mathrm{D}$ and $\mathrm{CD}_{4}$ in Clusius' laboratory $[19,20,22,38]$ and in his laboratory a series of determinations of the vapor pressure of $\mathrm{CH}_{3} \mathrm{D}$ was made over a very narrow range [21]. In table 5 is shown a comparison of the reported triple point temperatures and pressures. There is very good agreement between the values found at the Bureau, as calculated on the basis of a recent analysis of the samples, and those reported by Clusius and Wiegand which appear to be the most reliable results from Clusius' laboratory. In figure 2 are shown the vapor pressure data on the deuteromethanes, plotted as the function $T \log { }_{10} P_{\mathrm{D}} / P_{\mathrm{H}}$ where $P_{\mathrm{D}}$ is the vapor pressure of the deuterium compound and $P_{\mathrm{H}}$ the vapor pressure of $\mathrm{CH}_{4}$ at the 
TABLE 5. Triple point temperatures and pressures of the deuteromethanes

\begin{tabular}{|c|c|c|c|c|c|c|c|c|}
\hline \multirow{2}{*}{ Observer } & \multicolumn{2}{|c|}{$\mathrm{CH}_{3} \mathrm{D}$} & \multicolumn{2}{|c|}{$\mathrm{CH}_{2} \mathrm{D}_{2}$} & \multicolumn{2}{|c|}{$\mathrm{CHD}_{3}$} & \multicolumn{2}{|c|}{$\mathrm{CD}_{4}$} \\
\hline & $\Delta T_{\mathrm{a}}$ & $\Delta P^{\mathrm{a}}$ & $\Delta T$ & $\Delta P$ & $\Delta T$ & $\Delta P$ & $\Delta T$ & $\Delta P$ \\
\hline $\begin{array}{c}\text { Kruis, Popp, and Clusius } \\
{[19]}\end{array}$ & & & & & & & 1.46 & \\
\hline Clusius, Popp, and Frank & & & & & & & & \\
\hline Clusius and Wiegand [22]. & 0.08 & $\begin{array}{l}\text { 3. } 1 \\
\text { 3. } 1\end{array}$ & & & & & $\begin{array}{l}1.36 \\
.88\end{array}$ & $\begin{array}{l}8.6 \\
8.6\end{array}$ \\
\hline Clusius and Popp $[38]$ & .24 & 3. 0 & & & & & .88 & 8.6 \\
\hline $\begin{array}{l}\text { Brickwedde and Scott } \\
\text { (section 2) }\end{array}$ & 254 & 2.98 & 0.492 & 5. 47 & 0.701 & 17.31 & .865 & \\
\hline Selected best values.. & .25 & 3. 0 & .49 & 5.5 & .70 & 7.3 & .87 & 8.4 \\
\hline
\end{tabular}

sThe triple point temperature of the deuteromethane is $90.66-\Delta T^{\circ} \mathrm{K}$, and the triple point pressure of the deuteromethane is $87.50-\Delta P \mathrm{~mm}$.

TABLE 6. Constants for the equations $T \log _{10} P_{\mathrm{D}} / P_{\mathrm{H}}=A-B / T$

\begin{tabular}{|c|c|c|c|c|c|}
\hline \multirow{2}{*}{ Pure sukstance } & \multicolumn{2}{|c|}{ Solid range } & \multicolumn{2}{|c|}{ Liquid range } & \multirow{2}{*}{$\epsilon(\mathrm{mm})$} \\
\hline & $A$ & $B$ & $A$ & $B$ & \\
\hline $\begin{array}{l}\mathrm{CH}_{3} \mathrm{D} \\
\mathrm{CH}_{2} \mathrm{D}_{2} \\
\mathrm{CH}_{3} \mathrm{HD}_{3} \\
\mathrm{CD}_{4}\end{array}$ & $\begin{array}{l}\text { 1. } 260 \\
\text { 2. } 694 \\
\text { 4. } 452 \\
\text { 5. } 529\end{array}$ & $\begin{array}{l}110.2 \\
222.2 \\
351.7 \\
410.5\end{array}$ & $\begin{array}{l}\text { 1. } 328 \\
2.671 \\
3.969 \\
5.159\end{array}$ & $\begin{array}{l}129.5 \\
245.4 \\
343.8 \\
421.1\end{array}$ & $\begin{array}{r} \pm 0.015 \\
.017 \\
.018 \\
.009\end{array}$ \\
\hline
\end{tabular}

same temperature. The experimental NBS values are shown as circles; the area covered by the data of Clusius and Wiegand on $\mathrm{CH}_{3} \mathrm{D}$ is shown by a dotted rectangle. The spread of their data overlaps the NBS data, though the average is higher. The large spread represented by their data is probably a result of measurement of absolute vapor pressures only, with an accuracy of $0.1 \mathrm{~mm}$. A considerably more accurate measurement of the differences between the methanes was achieved at the NBS by the use of differential oil manometers.

Best values for the triple point temperatures and pressures were selected by comparison of the values given in table 5. For values of the vapor pressure at other temperatures, in the absence of other data, constants for eq (4) have been derived as described in section 2 on the basis of the NBS data alone,

$$
T \log _{10} P_{\mathrm{D}} / P_{\mathrm{H}}=A-B / T
$$

using analysis 5 for the compositions of the samples. The constants for $\mathrm{CD}_{4}$ are derived on the bais of measurements on sample 1 only.

The constants $A$ and $B$ derived in this manner are shown in table 6 . These constants differ slightly from those previously reported [36] which were based on the use of the earlier less reliable analysis 4 . The mean deviations of the experimental points from these equations are also shown, $\epsilon$ being the deviation of $\Delta P_{(\mathbf{D}-\mathrm{H})}$ in $\mathrm{mm} \mathrm{Hg}$. One source of uncertainty whose effect is not indicated by the deviations is the uncertainty of composition of the samples. The good agreement between the calculated values for the vapor pressure of $\mathrm{CD}_{4}$, based upon measurements made on two samples of widely differing composition, is an indication that the uncertainty due to lack of knowledge of the composition

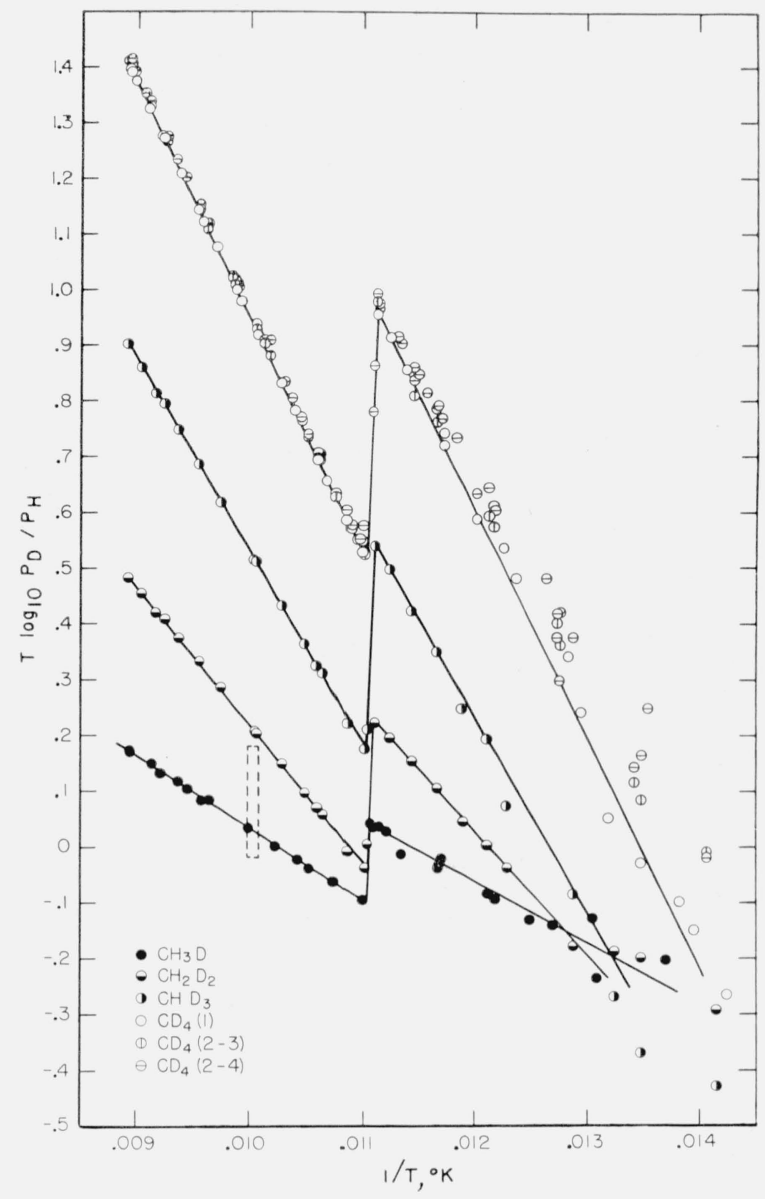

FiguRE 2. Vapor pressures of the pure deuteromethanes.

of the $\mathrm{CD}_{4}$ samples is very small. The greatest uncertainty in the vapor pressure difference $\Delta P_{\left(\mathrm{CH}_{3} \mathrm{D}-\mathrm{CH}_{4}\right)}$ is due to the lower limit of detectability of $\mathrm{CH}_{4}$ in the presence of $\mathrm{CH}_{3} \mathrm{D}$ by mass spectrometer, which is approximately two percent. The composition induced uncertainties in the vapor pressure differences $\Delta P_{\left(\mathrm{CH}_{2} \mathrm{D}_{2}-\mathrm{CH}_{4}\right)}$ and $\Delta P_{\left(\mathrm{CHD}_{3}-\mathrm{CH}_{4}\right)}$ are somewhat greater. While this uncertainty is difficult to assess, an estimate of an upper limit to it may be obtained by comparing the constants found as the results of several different attempts at analysis, and shown in table 10 of section 2 .

\section{Experimental Determination of the Vapor Pressures of Methane and the Deutero- methanes}

The experimental work on the measurement of the vapor pressures was carried out in the years 1935 to 1938 by F. G. Brickwedde and R. B. Scott. After the experiments were completed the samples of the deuteromethanes were retained in storage. Because new information for the interpretation of the observations became available, a new examination of 
the samples was undertaken in 1952 and a reevaluation of the data was carried out by G. T. Armstrong.

\subsection{Preparation of the Methane}

Six 4-liter samples of methane were prepared as indicated by the following reactions

(1) $2 \mathrm{CO}+2 \mathrm{D}_{2}=\mathrm{CD}_{4}+\mathrm{CO}_{2}$

(2) $\mathrm{CCl}_{4}+4 \mathrm{C}_{2} \mathrm{H}_{5} \overline{\mathrm{D}+}+4 \mathrm{Zn}=\mathrm{CD}_{4}+4 \mathrm{C}_{2} \mathrm{H}_{5} \mathrm{OZnCl}$

(3) $\mathrm{CHCl}_{3}+3 \mathrm{C}_{2} \mathrm{H}_{5} \mathrm{OD}+3 \mathrm{Zn=} \mathrm{CHD}_{3}+3 \mathrm{C}_{2} \mathrm{H}_{5} \mathrm{OZnCl}$

(4) $\mathrm{CH}_{2} \mathrm{I}_{2}+2 \mathrm{C}_{2} \mathrm{H}_{5} \mathrm{OD}+2 \mathrm{Zn}=\overline{\mathrm{CH}_{2} \mathrm{D}_{2}}+2 \mathrm{C}_{2} \mathrm{H}_{5} \mathrm{OZnI}$

(5) $\mathrm{CH}_{3} \mathrm{MgI}+\mathrm{D}_{2} \mathrm{O}=\mathrm{CH}_{3} \mathrm{D}+\overline{\mathrm{DOMg}} \mathrm{I}$

(6) $\mathrm{CCl}_{4}+4 \mathrm{C}_{2} \mathrm{H}_{5} \mathrm{OH} \overline{+4 \mathrm{Zn}}=\underline{\mathrm{CH}_{4}}+4 \mathrm{C}_{2} \mathrm{H}_{5} \mathrm{OZnCl}$.

All of these samples except (1) were prepared by Dr. Kiyoshi Morikawa at Princeton University. Sample 1 was prepared by Weber at Columbia University. The nonmethane impurities were removed from these samples by fractional distillation in a small lowtemperature still. For this work the still was surrounded by a liquid oxygen bath boiling at about 81 $\mathrm{cm} \mathrm{Hg}$. Two distillations were made on each sample. From the original 4-liter sample a middle fraction of 1.5 to 2 liters was collected in the first distillation and 300 to $500 \mathrm{~cm}^{3}$ in the second distillation. Before and after the collection of the middle or "pure" fraction of the second distillation, $200 \mathrm{~cm}^{3}$ fractions were collected. The vapor pressures of these $200 \mathrm{~cm}^{3}$ fractions at their boiling points did not differ from that of the middle fraction by as much as $0.1 \mathrm{~mm} \mathrm{Hg}$ and the difference was usually much smaller. This was regarded as evidence that impurities whose vapor pressures were very different from that of methane were not present in significant amounts in the "pure" fraction.

Another sample of $\mathrm{CH}_{4}$ was obtained by the fractional distillation of some relatively pure methane purchased from the Linde Air Products Co. This sample, $1,900 \mathrm{~cm}^{3}$, was used in all the vapor pressure work. The vapor pressure of this sample differed by less than $0.1 \mathrm{~mm} \mathrm{Hg}$ from the vapor pressures of the $200 \mathrm{~cm}^{3}$ samples collected immediately before and after it during the distillation. The vapor pressure of this material differed from that of the synthetic $\mathrm{CH}_{4}$ sample listed above by less than $0.1 \mathrm{~mm} \mathrm{Hg}$.

\subsection{Apparatus}

The vapor pressure of $\mathrm{CH}_{4}$ and the differences between the vapor pressures of the heavy methanes and $\mathrm{CH}_{4}$ were measured by means of the vapor pressure apparatus shown in figure 3. The copper block F, containing three cavities into which the methane samples were condensed, hangs in an evacuated vessel, D, which is surrounded by a bath of liquid air in the Dewar flask, I. The insulating vacuum in vessel $\mathrm{D}$ is produced by a vacuum pump at $\mathrm{A}$. The thin-walled copper-nickel tubes, $\mathrm{C}$, connect the cavities to the differential oil-manometer, J. One of the tubes also connects to the absolute mercury manometer, K. The temperature of the block is given by the small platinum resistance thermometer,

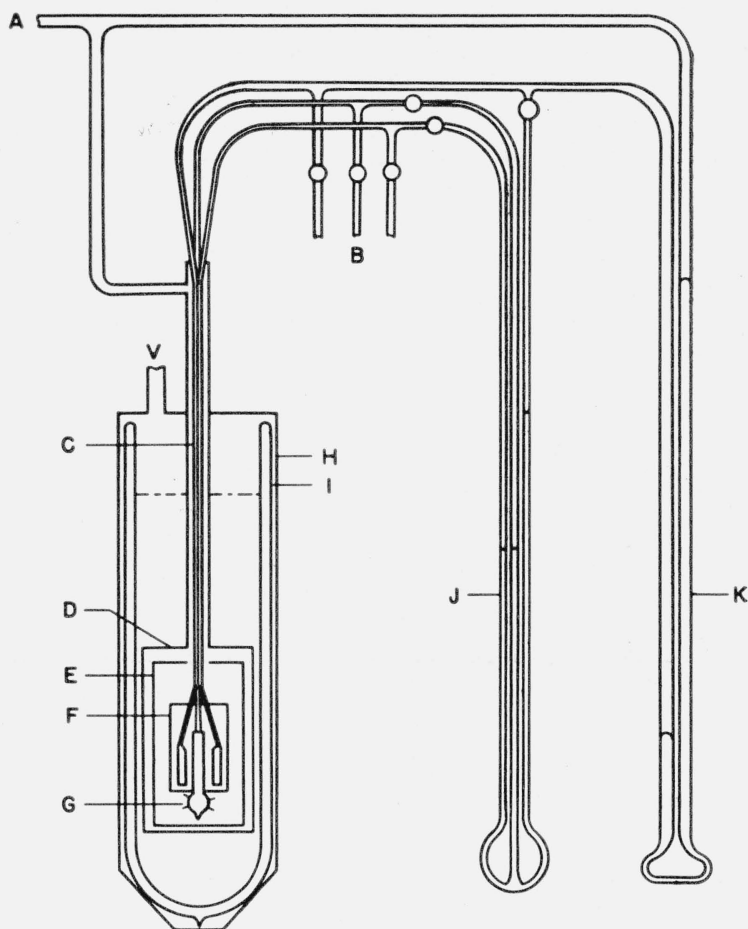

FiguRE 3. Differential vapor pressure apparatus.

A,, $\mathrm{V}$, Vacuum pump connections; B, filling tubes; C, thin-wall connecting tubes; D, evacuated vessel; $\mathrm{E}$, thermal shield; F, copper block; G, platinum resistance thermometer; $\mathrm{H}$, constant temperature bath enclosure; I, Dewar flask; J, differential oil manometer; K, absolute mercury manometer.

G. This thermometer is one of the standards which has been compared with the gas thermometer [39] between $10^{\circ}$ and $90^{\circ} \mathrm{K}$. Above $90^{\circ} \mathrm{K}$ the International Temperature Scale calibration was used. The temperature of the block is maintained uniform and constant by controlling the temperature of the thermal shield, E, which is equipped with electrical heaters and differential thermocouples. The temperature drift of the block was less than $0.0001 \mathrm{deg}$ per minute. To guard against cold spots on the tubes, C, they were wound with an electrical heater from a point at the top of the shield to a point above the level of the bath. A differential thermocouple, placed just below the lower end of the heater, was kept slightly warmer than the block.

The lowest temperatures, down to $54^{\circ} \mathrm{K}$, were obtained by reducing the pressure in vessel $\mathrm{H}$, containing the liquid air bath, by means of a large vacuum pump connected at V. Hydrogen at a few millimeters pressure was let into the insulating vacuum space while cooling the apparatus. It was found necessary, when working at the lower temperatures, to leave a little hydrogen in the insulating vacuum space to conduct away the heat flowing down the copper-nickel tubes. The various samples were introduced into the apparatus through the tubes B. Connections not shown in the diagram made possible the thorough evacuation of all the apparatus, so that the samples were not contaminated. A mercury displacement pump was employed in admitting and removing the samples. 
The vapor pressure readings were taken on mirror scales supported against the backs of the manometers. These scales could be read to $0.1 \mathrm{~mm}$. The absolute mercury manometer, $\mathrm{K}$, gave the vapor pressure of $\mathrm{CH}_{4}$; the differential oil manometer $\mathrm{J}$ measured the vapor pressure difference, heavy methane minus $\mathrm{CH}_{4}$. The oil in $\mathrm{J}$ is a diffusion pump oil having a very low vapor pressure and is chemically stable when heated to drive out dissolved gases. As an extra precaution against contamination of the liquid methane, while in the vapor pressure apparatus, by oil vapor, traps surrounded by solid $\mathrm{CO}_{2}$ were placed in the lines leading from the block to the manometers.

\subsection{Vapor Pressure-Temperature Relations for $\mathrm{CH}_{4}$}

The vapor pressure of $\mathrm{CH}_{4}$ was measured in the temperature range $54^{\circ}$ to $112^{\circ} \mathrm{K}$. If was found that the observations could be represented by the following equations ${ }^{3}$

$$
\begin{aligned}
& \mathrm{CH}_{\mathbf{s}} \text { (solid) : temperature range } 54^{\circ} \text { to } 90.66^{\circ} \mathrm{K} \\
& \log _{10} P(\mathrm{~mm} \mathrm{Hg})=6.7838-477.46 / T+ \\
& 0.00469 T
\end{aligned}
$$$$
\mathrm{CH}_{4} \text { (liquid): temperature range } 90.66^{\circ} \text { to } \mathrm{K} 112^{\circ}
$$$$
\log _{10} P(\mathrm{~mm} \mathrm{Hg})=7.55073-
$$$$
483.22 / T-0.0030686 T \text {. }
$$

The temperatures recorded on the International Temperature Scale were converted to degrees Kelvin using $T_{0}=273.16^{\circ} \mathrm{K}$. The deviations of the observations from the equations are shown in figure 4. These deviations may be considered as representing the errors in the measurement of vapor pressure since the precision of the resistance thermometer readings was such that the expected resultant scattering would be only $0.06 \mathrm{~mm} \mathrm{Hg}$ at the boiling point of $\mathrm{CH}_{4}$ and much less at lower temperatures. Constant errors resulting from inaccuracy of the temperature scale, should be considered separately. The temperatures

3 These equations deviate no more than $0.1 \mathrm{~mm}$ from eq (1) and (2) in section 1 , although different in form.

4 This oxygen was prepared by the thermal decomposition of thoroughly outgassed potassium permanganate. Its vapor pressure was compared with that of a sample prepared by the electrolytic dissociation of a carefully purified solution of barium hydroxide, Shepherd, Weaver, and Pickering, J. Research NBS 22, 301 (1939) RP1182. There was no significant difference in the vapor pressures of the two samples; less than $0.1 \mathrm{~mm} \mathrm{Hg}$

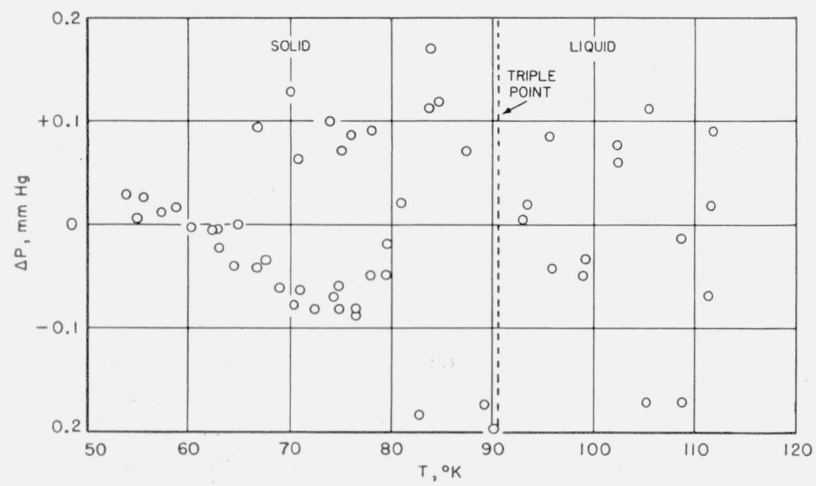

FIGURE 4. Deviations (obs-calc) of $\mathrm{CH}_{4}$ vapor pressure measurements from eq (5) and (6). given should be very reliable in the region near $90^{\circ}$ $\mathrm{K}$ since the resistance thermometer, while in the apparatus, was calibrated at the boiling point of oxygen. Pure oxygen ${ }^{4}$ was condensed into the vapor pressure apparatus and vapor pressure-resistance readings were taken in the neighborhood of the oxygen boiling point. Later calibrations of the resistance thermometer in the apparatus customarily used for oxygen boiling point calibrations on the International Temperature Scale, gave results which agreed to $0.005 \mathrm{deg}$ with the calibration in the methane apparatus.

A reasonable value for the uncertainty at temperatures near $90^{\circ} \mathrm{K}$ is $\pm 0.005^{\circ}$. At $111.6^{\circ} \mathrm{K}$ the estimated uncertainty is $\pm 0.010^{\circ} \mathrm{K}$ which corresponds to an error in vapor pressure of $\pm 0.6 \mathrm{~mm} \mathrm{Hg}$. At temperatures considerably below $90^{\circ} \mathrm{K}$ the uncertainty increases to $\pm 0.02^{\circ}$, but this is of no consequence since $d P / d T$ is so small that the over-all accuracy is limited by errors in the measurement of vapor pressure. The uncertainties in temperature given above do not take into account any error in the accepted value of the oxygen boiling point, which is taken to be $90.19^{\circ} \mathrm{K}$ or $-182.97^{\circ} \mathrm{C}$. Likewise, above the oxygen boiling point no consideration was given the possible deviations of the International Temperature Scale from the thermodynamic scale.

\subsection{Vapor Pressure Difference $\left(\mathrm{CH}_{n} \mathrm{D}_{4-n}-\mathrm{CH}_{4}\right)$}

The differences between the vapor pressures of the five samples of heavy methane and that of $\mathrm{CH}_{4}$ were investigated in the range of temperatures $54^{\circ}$ to $112^{\circ}$ K. The data are represented in the graphs, figure 5 .

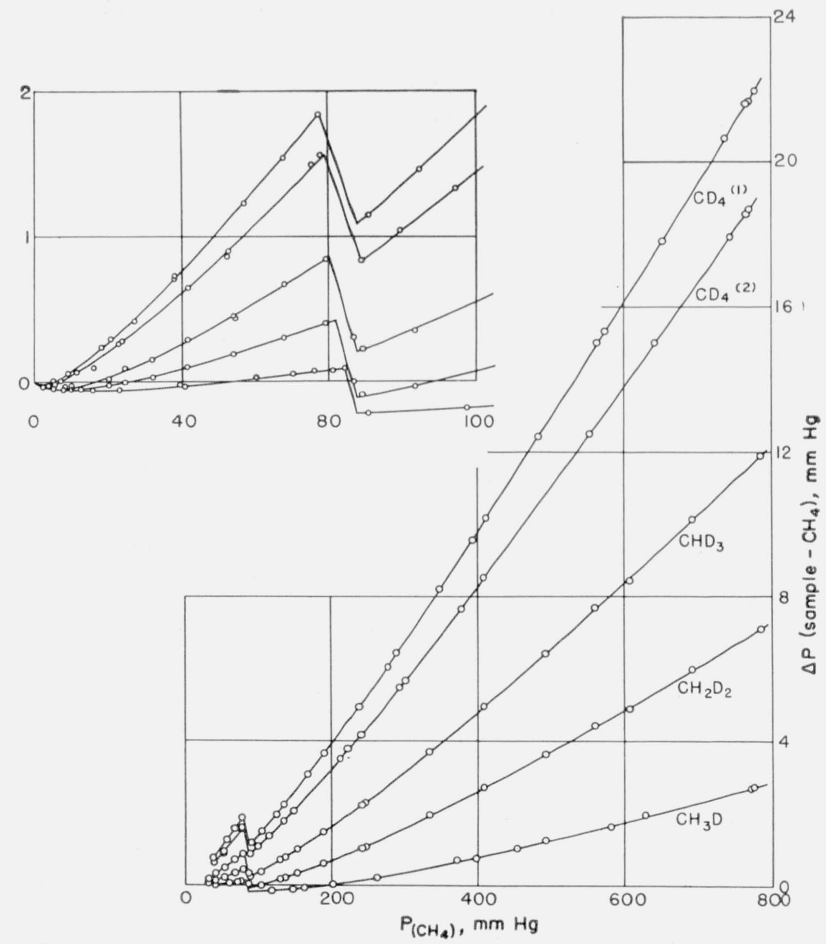

FiguRE 5. Vapor pressures of impure deuteromethane samples. The insert is an enlargement of the low pressure range. 
The deviations of the observed points from the smooth curves average less than $0.01 \mathrm{~mm} \mathrm{Hg}$. It will be noted that there are large differences between the values obtained for the two samples of $\mathrm{CD}_{4}$. A logical explanation of this discrepancy is that none of the samples were pure, but consisted of mixtures of the several isotopic modifications of methane.

\subsection{Triple Point Pressures and Temperatures}

The triple point pressures of the methanes were measured in the following manner: The sample was condensed into a spherical pyrex bulb of about 10 $\mathrm{cm}^{3}$ volume at the end of a tube $30 \mathrm{~cm}$ long, $5 \mathrm{~mm}$ inside diameter. This tube communicated with a mercury manometer. The sample was frozen with liquid air, then the liquid air flask was lowered until the vapor pressure started rising slowly. When the triple point was reached, the pressure would remain constant. The flat part of these pressure halts lasted from 2 to $5 \mathrm{~min}$, during which time the pressure was constant to the accuracy with which the manometer could be read. The first line of table 7 gives the observed triple point pressures and temperatures.

TABLE 7. Triple point temperatures and pressures of the deuteromethanes on the basis of several analyses a

$\Delta T$ is the difference $T_{\mathrm{CH}_{4}}$ minus $T_{\text {deuteromethane }}$ and $\Delta P$ is the difference $P_{\mathrm{CH}_{4}}$ minus $P_{\text {de uterometh ane. }} \quad T_{\mathrm{CH}_{4}}$ is $90.660^{\circ} ; P_{\mathrm{CH}_{4}}$ is $87.50 \mathrm{~mm}$.

\begin{tabular}{|c|c|c|c|c|c|c|c|c|}
\hline \multirow{2}{*}{ Designation } & \multicolumn{2}{|c|}{$\mathrm{CH}_{3} \mathrm{D}$} & \multicolumn{2}{|c|}{$\mathrm{CH}_{2} \mathrm{D}_{2}$} & \multicolumn{2}{|c|}{$\mathrm{CHD}_{3}$} & \multicolumn{2}{|c|}{$\mathrm{CD}_{4} \mathrm{~b}$} \\
\hline & $\Delta T$ & $\Delta P$ & $\Delta T$ & $\Delta P$ & $\Delta T$ & $\Delta P$ & $\Delta T$ & $\Delta P$ \\
\hline $\begin{array}{l}\text { Measured val- } \\
\text { ues.. } \\
\text { Analysis } 1 \\
\text { Analysis } 3 \\
\text { Analysis } 4 \\
\text { Analysis } 5\end{array}$ & $\begin{array}{r}0.254 \\
.285 \\
.254 \\
.254 \\
.254\end{array}$ & $\begin{array}{l}2.88 \\
3.36 \\
2.98 \\
2.98 \\
2.98\end{array}$ & $\begin{array}{r}0.460 \\
.509 \\
.483 \\
.509 \\
.492\end{array}$ & $\begin{array}{l}\text { 5. } 14 \\
\text { 5. } 65 \\
\text { 5. } 36 \\
\text { 5. } 70 \\
\text { 5. } 47\end{array}$ & $\begin{array}{r}0.606 \\
.656 \\
.687 \\
.711 \\
.701\end{array}$ & $\begin{array}{l}6.43 \\
6.87 \\
7.17 \\
7.38 \\
7.31\end{array}$ & $\begin{array}{r}0.849 \\
.865 \\
.867 \\
.864 \\
.865\end{array}$ & $\begin{array}{l}\text { 8. } 27 \\
8.38 \\
8.39 \\
8.37 \\
8.38\end{array}$ \\
\hline
\end{tabular}

a Values of $\Delta P(\mathrm{~mm})$ are significant to the nearest 10 th $\mathrm{mm} \mathrm{Hg}$.

b Calculated from measurements made on sample 1 .

\subsection{Analysis of the Sample}

Analysis of the deuteromethane samples in the mass spectrometer at Columbia University by Professor H. C. Urey and Dr. Marvin Fox revealed that the samples were indeed not pure. It was impossible to make a reliable analysis at that time because no mass spectrometer patterns of pure deuteromethanes were available for comparison. However an analysis was made based on assumptions regarding the mode of formation of ions of various masses. In the intervening years patterns for the deuteromethanes have been made in several laboratories and use has been made of these studies in determining more accurately the compositions of the samples. The various analyses that have been made are described below. The compositions found as the result of each analysis are listed in table 8.

Analysis 1. This analysis, based on patterns made at Columbia University by Professor Urey and Dr. Marvin Fox, was made entirely by a study of the abundance ratios of the various masses observed, without calibration patterns. The key to this
TABLE 8. Compositions of the deuteromethane samples

\begin{tabular}{|c|c|c|c|c|c|c|}
\hline \multirow{2}{*}{ Sample } & \multirow{2}{*}{ Analysis } & \multicolumn{5}{|c|}{ Component } \\
\hline & & $\mathrm{CH}_{4}$ & $\mathrm{CH}_{3} \mathrm{D}$ & $\mathrm{CH}_{2} \mathrm{D}_{2}$ & $\mathrm{CHD}_{3}$ & $\mathrm{CD}_{4}$ \\
\hline $\mathrm{CH}_{3} \mathrm{D}$ & $\begin{array}{l}1 \\
2 \\
3 \\
4(5)\end{array}$ & $\begin{array}{r}0.1074 \\
\ldots \ldots \\
\ldots \ldots\end{array}$ & $\begin{array}{l}0.8926 \\
1.00 \\
1.00 \\
1.00\end{array}$ & $\ldots$ & $\begin{array}{l}\ldots . . . \\
\cdots \cdots \\
\cdots \cdots\end{array}$ & - \\
\hline $\mathrm{CH}_{2} \mathrm{D}_{2} \ldots$ & $\begin{array}{l}1 \\
2 \\
3 \\
4 \\
5\end{array}$ & $\begin{array}{l}.0115 \\
.060 \\
.00\end{array}$ & $\begin{array}{l}.1917 \\
.076 \\
.102 \\
.108 \\
.135\end{array}$ & $\begin{array}{c}0.7968 \\
.924 \\
895 \\
.785 \\
.860\end{array}$ & $\begin{array}{l}\text { Trace } \\
0.004 \\
.046 \\
.005\end{array}$ & 0.001 \\
\hline $\mathrm{CHD}_{3 \ldots} \ldots$ & $\begin{array}{l}1 \\
2 \\
3 \\
4 \\
5\end{array}$ & $\begin{array}{l}.0013 \\
.024 \\
.005 \\
.018\end{array}$ & $\begin{array}{l}.0309 \\
.022 \\
.107 \\
.053\end{array}$ & $\begin{array}{l}.2567 \\
.335 \\
.283 \\
.277 \\
.288\end{array}$ & $\begin{array}{l}.7111 \\
.652 \\
.658 \\
.587 \\
.626\end{array}$ & $\begin{array}{l}.013 \\
.013 \\
.024 \\
.013\end{array}$ \\
\hline 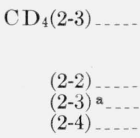 & $\begin{array}{c}1 \\
2 \\
3 \\
-4(5) \\
\end{array}$ & $\begin{array}{l}.0001 \\
\cdots \ldots \\
\cdots \cdots \\
\cdots \cdots\end{array}$ & $\begin{array}{l}.0044 \\
.058 \\
.040 \\
.037 \\
.038 \\
.039\end{array}$ & $\begin{array}{l}.0551 \\
.023 \\
.055 \\
.048 \\
.050 \\
.053\end{array}$ & $\begin{array}{l}3055 \\
.299 \\
.291 \\
.275 \\
.285 \\
.295\end{array}$ & $\begin{array}{l}.6349 \\
.618 \\
.614 \\
.638 \\
.626 \\
.613\end{array}$ \\
\hline $\mathrm{CD}_{4}(1) \ldots$ & $\begin{array}{l}1 \\
3 \\
4(5)\end{array}$ & - & 008 & $\begin{array}{l}.018 \\
.020 \\
.\end{array}$ & $\begin{array}{l}.0696 \\
.061 \\
.068\end{array}$ & $\begin{array}{l}.9284 \\
.919 \\
.924\end{array}$ \\
\hline
\end{tabular}

2. Values for sample 2-3 are interpolated as the mean of samples 2-2 and 2-4.

analysis was the presence in the $\mathrm{CD}_{4}$ patterns of mass 19. Assuming equal sensitivities for the parent masses of $\mathrm{CHD}_{3}$ and $\mathrm{CD}_{4}$, the $\mathrm{CHD}_{3}: \mathrm{CD}_{4}$ ratio was calculated from the amplitude ratio of mass 19 to mass 20. The purity of the deuterium used in the synthesis was estimated from this ratio to be 89.26 percent, and from this purity, the proportions of the remaining mixed deuteromethanes were estimated in the $\mathrm{CD}_{4}$ sample as well as the proportions of all the components in the other samples. This method was not thought to be very satisfactory because slight variations in its application to the various samples gave different compositions. The compositions of the $\mathrm{CD}_{4}$ samples thus determined were the most reliable, because the ratio of the two principal components was obtained with only the single assumption of equal ionization sensitivities.

Analysis 2. The mass patterns obtained in 1937 were reinterpreted, using calibration patterns determined by Mohler and Dibeler [40] for reference. This interpretation was subject to one error whose magnitude could not accurately be estimated: the original patterns were obtained on a Nier type mass spectrometer, while the reference patterns were obtained on a Consolidated Engineering Corporation instrument. The principal new feature revealed by this analysis was a much bigher purity for the $\mathrm{CH}_{3} \mathrm{D}$ than had been previously supposed. Instead of containing over 10 percent $\mathrm{CH}_{4}$ it was found to contain. little or no $\mathrm{CH}_{4}$. The $\mathrm{CH}_{2} \mathrm{D}_{2}$ and $\mathrm{CHD}_{3}$ compositions were also rather sharply affected; however, little confidence could be placed in the results for these two compounds because of the complexity of the patterns. The amounts of the major components of the $\mathrm{CD}_{4}$ samples were changed but iittle, though more $\mathrm{CH}_{3} \mathrm{D}$ was indicated to be present in sample 2 than at first estimated. 
Analysis 3. The study of the deuteromethanes made by Schissler, Thompson, and Turkevich [41] on a Nier type mass spectrometer became available; and this was used also for interpretation of the original 1937 patterns. This analysis confirmed the high purity of the $\mathrm{CH}_{3} \mathrm{D}$ sample suggested by analysis 2 , and gave compositions for the $\mathrm{CD}_{4}$ samples in reasonable agreement with analyses 1 and 2 . However, the composition of the $\mathrm{CH}_{2} \mathrm{D}_{2}$ and $\mathrm{CHD}_{3}$ samples were not in good agreement with either analysis 1 or 2 , and this fact suggested the desirability of making a new analysis of the original specimens of methane.

Analysis 4. The original samples were reanalyzed using the National Bureau of Standards Consolidated Engineering Company mass spectrometer. The material used in the previous analysis of the $\mathrm{CD}_{4}$ sample 2 , fraction 3 , from the final purification distillation, was no longer available. However, the neighboring fractions 2 and 4 were analyzed, and their compositions are shown in table 8 as samples 2-2 and 2-4. The differences are apparently due to the slight separation that occurred in the distillation. The composition of fraction 3 was taken as the average of fractions 2 and 4 . The composition thus found does not differ by more than 1 percent in any component from analysis 3 . The $\mathrm{CH}_{2} \mathrm{D}_{2}$ and $\mathrm{CHD}_{3}$ samples showed only a general correpondence to any of the preceding analyses, differences ranging as high as 11 percent. This analysis is subject to two criticisms: the analyses were not accompanied by calibration patterns, and the samples had been standing in glass bulbs closed by stopcocks for approximately 15 years and might have changed in composition. In each of the samples was found more or less nitrogen, which presumably entered by leakage of air. Oxygen was absent, apparently having been absorbed by the stopcock grease. The validity of the present analyses for the samples as studied in the vapor pressure work can be argued from the almost exact agreement of analysis 4 of the $\mathrm{CD}_{4}$ samples $2-2$ and $2-4$ with analysis 3 , and also from the fact that the $\mathrm{CD}_{4}$ content of the $\mathrm{CHD}_{3}$ did not show any increase over the years. The analyses of the $\mathrm{CH}_{2} \mathrm{D}_{2}$ and $\mathrm{CHD}_{3}$ samples were still considered to be unsatisfactory because the materials used in the previous studies of the mass spectra were of rather low purity.

Analysis 5. Samples of pure $\mathrm{CH}_{2} \mathrm{D}_{2}$ and $\mathrm{CHD}_{3}$ prepared by D. H. Rank of Pennsylvania State College became available for making mass spectrometer studies in 1953. Because these were much better samples than had been previously used for comparison, and because it became possible to make a calibration pattern at the same time an analysis was made, the first objection to analysis 4 could be removed. A final analysis of the $\mathrm{CH}_{2} \mathrm{D}_{2}$ and $\mathrm{CHD}_{3}$ was made using the Rank samples for comparison. The new analyses are closer to analysis 3 than to any other, and no component differs by more than 4 percent from that given in analysis 3. Analysis 5 must be considered to be the most reliable on account of the way it was made, though still subject to some possibility that the samples have altered in the long period since the vapor pressure work was done.

\subsection{Treatment of the Vapor Pressure Data}

With the information given by the analyses concerning the compositions of the various samples whose properties were measured, it is possible to calculate the properties of the pure materials. In order to do this it is necessary, in the absence of contrary information, to assume the solutions to be ideal. In this circumstance an observed property, linear in the mole fractions of the components, will be given in terms of the corresponding properties of the pure components and their mole fractions by equations of the following type

$$
\begin{gathered}
\Delta P(1)=n(1)_{\mathrm{CH}_{3} \mathrm{D}} \Delta P^{\circ}{ }_{\mathrm{CH}_{3} \mathrm{D}}+n(1)_{\mathrm{CH}_{2} \mathrm{D}_{2}} \Delta P^{\circ}{ }_{\mathrm{CH}_{2} \mathrm{D}_{2}}+ \\
n(1)_{\mathrm{CHD}_{3}} \Delta P^{\circ}{ }_{\mathrm{CHD}_{3}}+n(1)_{\mathrm{CD}_{4}} \Delta P^{\circ}{ }_{\mathrm{CD}_{4}} .
\end{gathered}
$$

The number in parenthesis refers to the sample under consideration and the subscript compound refers to the component, $n$ is the mole fraction and in this instance $\Delta P$ and $\Delta P^{\circ}$ are respectively the difference of the vapor pressure of the sample and of the pure component from the vapor pressure of $\mathrm{CH}_{4}$. A total of six simultaneous equations of this type were found for the six samples on which analyses and vapor pressure studies were made. Using the mole fractions given by analysis 5 these equations were solved four at a time for the values of $\Delta P^{\circ}$ for the various components. The solutions are given below

$$
\begin{aligned}
\text { (a) } \Delta P^{\circ}{ }_{\mathrm{CH}_{3} \mathrm{D}}= & \Delta P\left(\mathrm{CH}_{3} \mathrm{D}\right) . \\
\text { (b) } \Delta P^{\circ}{ }_{\mathrm{CH}_{2} \mathrm{D}_{2}}= & -0.157 \Delta P\left(\mathrm{CH}_{3} \mathrm{D}\right)+1.166 \Delta P \\
& \left(\mathrm{CH}_{2} \mathrm{D}_{2}\right)-0.009 \Delta P\left(\mathrm{CHD}_{3}\right) \\
& +0.001 \Delta P\left(\mathrm{CD}_{4}\right) . \\
\text { (c) } \Delta P^{\circ}{ }_{\mathrm{CHD}_{3}}= & -0.012 \Delta P\left(\mathrm{CH}_{3} \mathrm{D}\right)+0.538 \Delta P \\
& \left(\mathrm{CH}_{2} \mathrm{D}_{2}\right)+1.602 \Delta P\left(\mathrm{CHD}_{3}\right) \\
& -0.023 \Delta P\left(\mathrm{CD}_{4}\right) .
\end{aligned}
$$
(d) $\Delta P^{\circ}{ }_{\mathrm{CD}_{4}}(1)=-0.008 \Delta P\left(\mathrm{CH}_{3} \mathrm{D}\right)+0.040 \Delta P$ $\left(\mathrm{CH}_{2} \mathrm{D}_{2}\right)-0.118 \Delta P\left(\mathrm{CHD}_{3}\right)$ $+1.084 \Delta P\left(\mathrm{CD}_{4}\right)$. (e) $\Delta P_{\mathrm{CD}_{4}}^{\circ}(2-3)=\frac{-0.043 \Delta P\left(\mathrm{CH}_{3} \mathrm{D}\right)+0.153 \Delta P}{\left(\mathrm{CH}_{2} \mathrm{D}_{2}\right)-0.735 \Delta P\left(\mathrm{CHD}_{3}\right)}$ $+1.613 \Delta P\left(\mathrm{CD}_{4}\right)$.
(f) $\Delta P_{\mathrm{CD}_{4}}^{\circ}(2-4)=-0.045 \Delta P\left(\mathrm{CH}_{3} \mathrm{D}\right)+0.160 \Delta P$ $\left(\mathrm{CH}_{2} \mathrm{D}_{2}\right)-0.776 \Delta P\left(\mathrm{CHD}_{3}\right)$ $+1.648 \Delta P\left(\mathrm{CD}_{4}\right)$.

In applying eq (b) and (c) the $\mathrm{CD}_{4}$ sample data required for the evaluation of $\Delta P^{\circ}$ are those obtained from sample 1 which, on account of its greater purity, was used in deriving the equations. In eq $(\mathrm{d}, \mathrm{e}, \mathrm{f})$ the $\mathrm{CD}_{4}$ sample data to be used is indicated in parenthesis.

It is necessary to know the values of the vapor pressures of all the samples at the same temperatures in order to use eq (a-f). Advantage was taken of the 
TABLE $9-\mathrm{A}^{\mathrm{a}} \quad \mathrm{CH}_{3} \mathrm{D}$

\begin{tabular}{|c|c|c|c|c|c|}
\hline$P_{\mathrm{CH} 4}$ & $\triangle P(\mathrm{obs})$ & $\triangle P^{\circ}$ & $\log _{10} P_{\mathrm{D}} / P_{\mathrm{H}}$ & $T \log _{10} P_{\mathrm{D}} / P_{\mathrm{H}}$ & $1 / T$ \\
\hline \multicolumn{6}{|c|}{ Solid range } \\
\hline $\begin{array}{r}39.39 \\
60.08 \\
76.06 \\
3.85 \\
8.20 \\
15.71 \\
24.18 \\
40.95 \\
70.26 \\
7.88 \\
12.41 \\
22.56 \\
22.96 \\
40.62 \\
81.11 \\
84.52\end{array}$ & $\begin{array}{r}-0.024 \\
+.023 \\
+.071 \\
-.025 \\
-.033 \\
-.060 \\
-.057 \\
-.044 \\
+.048 \\
-.057 \\
-.051 \\
-.060 \\
-.060 \\
-.038 \\
+.073 \\
+.088\end{array}$ & $\begin{array}{r}-0.024 \\
+.023 \\
+.071 \\
-.025 \\
-.033 \\
-.060 \\
-.057 \\
-.044 \\
+.048 \\
-.057 \\
-.051 \\
-.060 \\
-.060 \\
-.038 \\
+.073 \\
+.088\end{array}$ & $\begin{array}{r}-0.00027 \\
+.00017 \\
+.00040 \\
-.00281 \\
-.00175 \\
-.00165 \\
-.00104 \\
-.00046 \\
+.00030 \\
-.00314 \\
-.00179 \\
-.00115 \\
-.00113 \\
-.00041 \\
+.00038 \\
+.00045\end{array}$ & $\begin{array}{r}-0.023 \\
+.015 \\
+.036 \\
-.205 \\
-.130 \\
-.132 \\
-.086 \\
-.039 \\
+.027 \\
-.237 \\
-.142 \\
-.094 \\
-.093 \\
-.035 \\
+.034 \\
+.041\end{array}$ & $\begin{array}{r}0.011706 \\
.011348 \\
.011149 \\
.013699 \\
.013047 \\
.012490 \\
.012121 \\
.011673 \\
.011216 \\
.013081 \\
.012691 \\
.012180 \\
.012165 \\
.011680 \\
.011095 \\
.011064\end{array}$ \\
\hline \multicolumn{6}{|c|}{ Liquid range } \\
\hline $\begin{array}{l}147.12 \\
260.26 \\
454.20 \\
117.58 \\
163.91 \\
372.03 \\
493.18 \\
627.92 \\
774.54 \\
90.54 \\
202.02 \\
398.15 \\
581.80 \\
770.34\end{array}$ & $\begin{array}{r}-0.142 \\
+.192 \\
+1.002 \\
-.185 \\
-.095 \\
+. .682 \\
+1.231 \\
+1.954 \\
+2.720 \\
-.221 \\
+.000 \\
+. .720 \\
+1.606 \\
+2.683\end{array}$ & $\begin{array}{r}-0.142 \\
+.192 \\
+1.002 \\
-.185 \\
-.095 \\
+.682 \\
+1.231 \\
+1.954 \\
+2.720 \\
-.221 \\
+.000 \\
+.720 \\
+1.606 \\
+2.683\end{array}$ & $\begin{array}{r}-0.000421 \\
+.000321 \\
+.000958 \\
-.000681 \\
-.000252 \\
+.000794 \\
+.001084 \\
+.001349 \\
+.001522 \\
+.001058 \\
+.000000 \\
+.000785 \\
+.001197 \\
+.001509\end{array}$ & $\begin{array}{l}-0.0400 \\
+.0321 \\
+.1013 \\
-.0633 \\
-.0242 \\
+.0823 \\
+.1156 \\
+.1476 \\
+.1703 \\
-.0962 \\
+.0000 \\
+.0819 \\
+.1299 \\
+.1688\end{array}$ & $\begin{array}{l}0.010537 \\
.009991 \\
.009455 \\
.010751 \\
.010434 \\
.009648 \\
.009375 \\
.009141 \\
.008937 \\
.010999 \\
.010234 \\
.009582 \\
.009215 \\
.008942\end{array}$ \\
\hline
\end{tabular}

a In tables $9 \mathrm{~A}-9 \mathrm{~F}$ the values for $P_{\mathrm{CH} 4}$ are significant to the nearest tenth of a mm Hg. The values for $\triangle P($ obs $)$ and $\triangle P^{\circ}$ are significant to the nearest hundredth $\mathrm{mm} \mathrm{Hg}$. The derived quantities $\log _{10} P_{\mathrm{D}} / P_{\mathrm{H}}$ and $T \log _{10} P_{\mathrm{D}} / P_{\mathrm{H}}$ have generally the same number of significant figures as $\triangle P^{\circ}$.

Table 9-B. $\mathrm{CH}_{2} \mathrm{D}_{2}$

\begin{tabular}{|c|c|c|c|c|c|}
\hline$P_{\mathrm{CH} 4}$ & $\triangle P(\mathrm{obs})$ & $\triangle P^{\circ}$ & $\log _{10} P_{\mathrm{D}} / P_{\mathrm{H}}$ & $T \log _{10} P_{\mathrm{D}} / P_{\mathrm{H}}$ & $1 / T$ \\
\hline \multicolumn{6}{|c|}{ Solid range } \\
\hline $\begin{array}{r}2.29 \\
4.99 \\
20.01 \\
31.81 \\
53.92 \\
79.25 \\
2.82 \\
6.55 \\
10.04 \\
24.39 \\
41.68 \\
67.75\end{array}$ & $\begin{array}{r}-0.022 \\
-.031 \\
-.026 \\
+.026 \\
+.189 \\
+.401 \\
-.038 \\
-.054 \\
-.006 \\
+.098 \\
+.300\end{array}$ & $\begin{array}{r}-0.022 \\
-.031 \\
-.021 \\
+.038 \\
+.217 \\
+.451 \\
-.038 \\
-.053 \\
+.001 \\
+.116 \\
+.340\end{array}$ & $\begin{array}{l}-0.0042 \\
-.0027 \\
-.00046 \\
+.00052 \\
+.00175 \\
+.00247 \\
-.0025 \\
-.0023 \\
+.00002 \\
+.00121 \\
+.00218\end{array}$ & $\begin{array}{r}-0.296 \\
-.200 \\
-.038 \\
+.044 \\
+.153 \\
+.222 \\
-.189 \\
-.179 \\
+.002 \\
+.104 \\
+.194\end{array}$ & $\begin{array}{r}0.014149 \\
.013475 \\
.012283 \\
.011888 \\
.011440 \\
.011114 \\
.013240 \\
.012873 \\
.012113 \\
.011666 \\
.011247\end{array}$ \\
\hline \multicolumn{6}{|c|}{ Liquid range } \\
\hline $\begin{array}{r}784.20 \\
86.78 \\
129.90 \\
189.77 \\
334.41 \\
493.13 \\
692.31 \\
88.96 \\
136.85 \\
240.79 \\
607.75 \\
103.44 \\
153.49 \\
245.53 \\
408.98 \\
560.24\end{array}$ & $\begin{array}{r}+7.104 \\
-.001 \\
+.142 \\
+.578 \\
+1.918 \\
+3.615 \\
+5.979 \\
-.095 \\
+.177 \\
+.998 \\
+4.901 \\
-.035 \\
+.300 \\
+1.034 \\
+2.693 \\
+4.425\end{array}$ & $\begin{array}{r}+7.75 \\
+.01 \\
+.18 \\
+.67 \\
+2.13 \\
+3.98 \\
+6.54 \\
-.09 \\
+.23 \\
+1.13 \\
+5.38 \\
-.02 \\
+.36 \\
+1.17 \\
+2.98 \\
+4.86\end{array}$ & $\begin{array}{r}+0.00429 \\
+.00004 \\
+.00061 \\
+.00152 \\
+.00277 \\
+.00350 \\
+.00410 \\
.00043 \\
+.00073 \\
+.00203 \\
+.00384 \\
+.00009 \\
+.00100 \\
+.00207 \\
+.00316 \\
+.00376\end{array}$ & $\begin{array}{r}+0.481 \\
+.004 \\
+.057 \\
+.148 \\
+.284 \\
+.374 \\
+.453 \\
-.039 \\
+.069 \\
+.202 \\
+.418 \\
+.008 \\
+.095 \\
+.206 \\
+.331 \\
+.407\end{array}$ & $\begin{array}{l}0.008924 \\
.011039 \\
.010656 \\
.010294 \\
.009750 \\
.009375 \\
.009046 \\
.011016 \\
.010605 \\
.010066 \\
.009172 \\
.010872 \\
.010497 \\
.010047 \\
.009556 \\
.009251\end{array}$ \\
\hline
\end{tabular}

TABLe 9-C. $\mathrm{CHD}_{3}$

\begin{tabular}{|c|c|c|c|c|c|}
\hline$P_{\mathrm{CH} 4}$ & $\triangle P(\mathrm{obs})$ & $\triangle P^{\circ}$ & $\log _{10} P_{\mathrm{D}} / P_{\mathrm{H}}$ & $T \log _{10} P_{\mathrm{D}} / P_{\mathrm{H}}$ & $1 / T$ \\
\hline \multicolumn{6}{|c|}{ Solid range } \\
\hline $\begin{array}{r}2.29 \\
4.99 \\
20.01 \\
31.81 \\
53.92 \\
79.25 \\
2.82 \\
6.55 \\
10.04 \\
24.39 \\
41.28 \\
67.75\end{array}$ & $\begin{array}{r}-0.032 \\
-.044 \\
+.014 \\
+.150 \\
+.451 \\
+.844 \\
-. .044 \\
-.025 \\
+.090 \\
+.288 \\
+.670\end{array}$ & $\begin{array}{r}-0.032 \\
-.058 \\
+.040 \\
+.214 \\
+.599 \\
+1.091 \\
-.054 \\
-.026 \\
+.130 \\
+.386 \\
+.870\end{array}$ & $\begin{array}{c}-0.0061 \\
-.0050 \\
+.0009 \\
+.00242 \\
+.00482 \\
+.00598 \\
-.0036 \\
-.0011 \\
+.00231 \\
+.00406 \\
+.00558\end{array}$ & $\begin{array}{l}-0.43 \\
-.37 \\
+.072 \\
+.246 \\
+.421 \\
+.538 \\
-.27 \\
-.086 \\
+.191 \\
+.348 \\
+.496\end{array}$ & $\begin{array}{r}0.014149 \\
.013475 \\
.012283 \\
.011888 \\
.011440 \\
.011114 \\
-.013240 \\
.012873 \\
.012113 \\
.011666 \\
.011247\end{array}$ \\
\hline \multicolumn{6}{|c|}{ Liquid range } \\
\hline $\begin{array}{r}784.20 \\
86.78 \\
129.90 \\
189.77 \\
334.41 \\
493.13 \\
692.31 \\
88.96 \\
136.85 \\
240.79 \\
607.75 \\
103.44 \\
153.49 \\
245.53 \\
408.98 \\
560.24\end{array}$ & $\begin{array}{r}11.887 \\
.300 \\
.678 \\
1.456 \\
3.677 \\
6.405 \\
10.122 \\
.221 \\
.745 \\
2.191 \\
8.427 \\
.348 \\
.964 \\
2.244 \\
4.944 \\
7.672\end{array}$ & $\begin{array}{r}14.66 \\
.46 \\
.99 \\
1.95 \\
4.67 \\
8.01 \\
12.52 \\
.39 \\
1.08 \\
2.86 \\
10.50 \\
.57 \\
1.34 \\
2.92 \\
6.21 \\
9.55\end{array}$ & $\begin{array}{r}+0.00804 \\
.00230 \\
.00330 \\
.00443 \\
.00602 \\
.00699 \\
.00778 \\
.00191 \\
.00341 \\
.00513 \\
.00744 \\
.00239 \\
.00380 \\
.00514 \\
.00654 \\
.00734\end{array}$ & $\begin{array}{r}0.901 \\
.208 \\
.310 \\
.431 \\
.617 \\
.747 \\
.860 \\
.173 \\
.322 \\
.510 \\
.812 \\
.220 \\
.362 \\
.512 \\
.685 \\
.794\end{array}$ & $\begin{array}{l}0.008924 \\
.011039 \\
.010656 \\
.010294 \\
.009750 \\
.009375 \\
.009046 \\
.011016 \\
.010605 \\
.010066 \\
.009172 \\
.010872 \\
.010497 \\
.010047 \\
.009556 \\
.009251\end{array}$ \\
\hline
\end{tabular}

TABLE 9-D. $\mathrm{CD}_{4}$ (sample 1)

\begin{tabular}{|c|c|c|c|c|c|}
\hline$P_{\mathrm{CH} 4}$ & $\triangle P(\mathrm{obs})$ & $\triangle P^{\circ}$ & $\log _{10} P_{\mathrm{D}} / P_{\mathrm{H}}$ & $T \log _{10} P_{\mathrm{D}} / P_{\mathrm{H}}$ & $1 / T$ \\
\hline \multicolumn{6}{|c|}{ Solid range } \\
\hline $\begin{array}{r}7.07 \\
10.60 \\
20.56 \\
27.00 \\
37.95 \\
56.68 \\
67.36 \\
2.06 \\
2.89 \\
3.36 \\
5.04 \\
9.25 \\
18.18 \\
38.05 \\
77.33\end{array}$ & $\begin{array}{r}+0.003 \\
+.095 \\
+.294 \\
+.417 \\
+.730 \\
+1.228 \\
+1.545 \\
-.019 \\
-.016 \\
-.013 \\
+.006 \\
+.0057 \\
+.234 \\
+.710 \\
+1.838\end{array}$ & $\begin{array}{r}+0.011 \\
+.105 \\
+.312 \\
+.442 \\
+.766 \\
+1.283 \\
+1.611 \\
-.018 \\
-.014 \\
-.011 \\
+.012 \\
+.066 \\
+.250 \\
+.746 \\
+1.911\end{array}$ & $\begin{array}{l}+0.0007 \\
+.0043 \\
+.00654 \\
+.00705 \\
+.00868 \\
+.00973 \\
+.01026 \\
-.0038 \\
-.0021 \\
-.0014 \\
+.0010 \\
+.0031 \\
+.00593 \\
+.00843 \\
+.01060\end{array}$ & $\begin{array}{l}+0.05 \\
+.34 \\
+.534 \\
+.586 \\
+.740 \\
+.854 \\
+.912 \\
-.267 \\
-.151 \\
-.10 \\
+.07 \\
+.24 \\
+.480 \\
+.718 \\
+.954\end{array}$ & $\begin{array}{r}0.013175 \\
.012827 \\
.012259 \\
.012027 \\
.011737 \\
.011397 \\
.011252 \\
.014240 \\
.013947 \\
.013816 \\
.013466 \\
.012944 \\
.012364 \\
.011735 \\
.011135\end{array}$ \\
\hline \multicolumn{6}{|c|}{ Liquid range } \\
\hline $\begin{array}{r}737.80 \\
738.02 \\
768.25 \\
90.65 \\
104.54 \\
135.63 \\
168.33 \\
237.88 \\
289.08 \\
348.56 \\
413.30 \\
485.23 \\
564.61 \\
652.72 \\
124.58 \\
190.59 \\
276.97 \\
393.97 \\
575.05 \\
765.71 \\
776.90\end{array}$ & $\begin{array}{r}20.636 \\
20.629 \\
21.656 \\
-1.150 \\
+1.462 \\
2.207 \\
3.044 \\
4.922 \\
6.415 \\
8.183 \\
10.162 \\
12.411 \\
14.991 \\
17.819 \\
1.926 \\
3.630 \\
6.036 \\
9.545 \\
15.309 \\
21.590 \\
21.950\end{array}$ & $\begin{array}{r}21.314 \\
21.307 \\
22.364 \\
1.219 \\
1.544 \\
2.321 \\
3.181 \\
5.120 \\
6.660 \\
8.482 \\
10.524 \\
12.843 \\
15.502 \\
18.416 \\
2.025 \\
3.787 \\
6.269 \\
9.888 \\
15.821 \\
22.306 \\
22.676\end{array}$ & $\begin{array}{l}0.01236 \\
.01235 \\
.01246 \\
.00580 \\
.00636 \\
.00737 \\
.00813 \\
.00925 \\
.00988 \\
.01045 \\
.01092 \\
.01135 \\
.01177 \\
.01208 \\
.00699 \\
.00854 \\
.00973 \\
.01076 \\
.01178 \\
.01247 \\
.01249\end{array}$ & $\begin{array}{r}1.376 \\
1.375 \\
1.392 \\
.528 \\
.585 \\
.693 \\
.782 \\
.918 \\
.999 \\
1.076 \\
1.143 \\
1.209 \\
1.272 \\
1.326 \\
.654 \\
.831 \\
.978 \\
1.121 \\
1.276 \\
1.393 \\
1.396\end{array}$ & $\begin{array}{r}0.008984 \\
.008984 \\
.008945 \\
.010998 \\
.010862 \\
.010615 \\
.010408 \\
.010078 \\
.009890 \\
.009710 \\
.009546 \\
.009391 \\
.009244 \\
.009103 \\
.010696 \\
.010290 \\
.009931 \\
.009592 \\
.009226 \\
.008948 \\
.008934\end{array}$ \\
\hline & & & & & \\
\hline
\end{tabular}


TABLE 9-E. $\mathrm{CD}_{4}$ (sample 2-3)

\begin{tabular}{|c|c|c|c|c|c|}
\hline$P_{\mathrm{CH} 4}$ & $\triangle P(\mathrm{obs})$ & $\Delta P^{\circ}$ & $\log _{10} P_{\mathrm{D}} / P_{\mathrm{H}}$ & $T \log _{10} P_{\mathrm{D}} / P_{\mathrm{H}}$ & $1 / T$ \\
\hline \multicolumn{6}{|c|}{ Solid range } \\
\hline $\begin{array}{r}2.54 \\
4.97 \\
11.85 \\
22.80 \\
39.00 \\
52.33 \\
52.57 \\
75.46 \\
5.36 \\
11.52 \\
23.89 \\
41.41 \\
77.69\end{array}$ & $\begin{array}{r}-0.016 \\
-.015 \\
+.066 \\
+.253 \\
+.599 \\
+.862 \\
+.900 \\
+1.497 \\
-.013 \\
+.063 \\
+.278 \\
+.646 \\
+1.562\end{array}$ & $\begin{array}{r}-0.001 \\
+.013 \\
+.129 \\
+.369 \\
+.795 \\
+1.127 \\
+1.166 \\
+1.890 \\
+.019 \\
+.123 \\
+.399 \\
+.855 \\
+1.970\end{array}$ & $\begin{array}{c}-0.00017 \\
+.0011 \\
+.0051 \\
+.00696 \\
+.00875 \\
+.00925 \\
+.00951 \\
+.01075 \\
+.00153 \\
+.00461 \\
+.00719 \\
+.00887 \\
+.01088\end{array}$ & $\begin{array}{l}-0.012 \\
+.082 \\
+.40 \\
+.573 \\
+.747 \\
+.807 \\
+.830 \\
+.964 \\
+.114 \\
+.361 \\
+.592 \\
+.760 \\
+.976\end{array}$ & $\begin{array}{l}0.014059 \\
.013478 \\
.012731 \\
.012171 \\
.011714 \\
.011465 \\
.011461 \\
.011156 \\
.013413 \\
.012755 \\
.012131 \\
.011664 \\
.011131\end{array}$ \\
\hline \multicolumn{6}{|c|}{ Liquid range } \\
\hline $\begin{array}{r}114.53 \\
99.52 \\
148.11 \\
212.25 \\
300.87 \\
409.34 \\
554.25 \\
768.66 \\
765.31 \\
135.81 \\
240.51 \\
378.50 \\
642.16 \\
88.73 \\
134.57 \\
223.83 \\
293.74\end{array}$ & $\begin{array}{r}1.333 \\
1.042 \\
2.026 \\
3.475 \\
5.653 \\
8.498 \\
12.490 \\
18.681 \\
18.551 \\
1.757 \\
4.144 \\
7.603 \\
14.993 \\
.836 \\
1.743 \\
3.754 \\
5.460\end{array}$ & $\begin{array}{r}1.798 \\
1.437 \\
2.661 \\
4.425 \\
7.043 \\
10.44 \\
15.19 \\
22.51 \\
22.37 \\
2.33 \\
5.23 \\
9.38 \\
18.17 \\
1.19 \\
2.30 \\
4.76 \\
6.81\end{array}$ & $\begin{array}{r}0.00676 \\
.00623 \\
.00773 \\
.00896 \\
.01005 \\
.01093 \\
.01175 \\
.01253 \\
.01251 \\
.00738 \\
.00934 \\
.01064 \\
.01212 \\
.00577 \\
.00736 \\
.00914 \\
.00994\end{array}$ & $\begin{array}{r}0.627 \\
.571 \\
.734 \\
.881 \\
1.020 \\
1.143 \\
1.267 \\
1.400 \\
1.398 \\
.695 \\
.927 \\
1.104 \\
1.329 \\
.523 \\
.693 \\
.902 \\
1.006\end{array}$ & $\begin{array}{r}0.010775 \\
.010909 \\
.010530 \\
.010187 \\
.009852 \\
.009555 \\
.009262 \\
.008944 \\
.008948 \\
.010613 \\
.010067 \\
.009631 \\
.009119 \\
.011018 \\
.010622 \\
.010136 \\
.009875\end{array}$ \\
\hline
\end{tabular}

fact that in each of these equations the contributions of all but one of the samples to the final value are relatively small. The vapor pressure differences $\Delta P$ were plotted for each sample as a function of $1 / T$. Values were taken from these graphs at 12 fixed points. The term $\left(\Delta P^{\circ}-\Delta P\right)$ was then calculated for each sample at these 12 fixed points on the basis of the relations (a-f) and were plotted against $1 / T$. From the resulting graphs interpolated values of $\Delta P^{\circ}-\Delta P$ were selected corresponding to each experimental point and when added to the experimental value of $\Delta P$ gave a value of $\Delta P^{\circ}$. The results of these calculations are shown in tables $9 \mathrm{~A}-9 \mathrm{~F}$.

By use of the coefficients found in eq (a-f) the triple point temperatures and pressures of the pure components were calculated and are shown in terms of their differences from $\mathrm{CH}_{4}$. The line drawn in figure 6 passes through the values thus determined in table 7 . In this calculation it was assumed that the triple point temperature and pressure of each sample are linear functions of the triple point temperatures and pressures of the pure components. By similar calculations the triple points of the pure components had been calculated on the basis of the other analyses. The short vertical lines in figure 6 indicate the spread resulting from the various analyses.

Three different functional relations were tried in an attempt to fit the data to equations. A plot of $\log _{10} P_{\mathrm{D}} / P_{\mathrm{H}}$ against $1 / T$ gives a definitely curved line in each case in the liquid range. A plot of $T \log _{10} P_{\mathrm{D}} / P_{\mathrm{H}}$ against $1 / T$ gave a very nearly straight line for each liquid. A calculation of constants for the equation $\log _{10} P_{\mathrm{D}} / P_{\mathrm{H}}=A-B / T+C T$ did not give
TABLE 9-F. $\mathrm{CD}_{4}$ (sample 2-4)

\begin{tabular}{|c|c|c|c|c|c|}
\hline$P_{\mathrm{CH}} 4$ & $\triangle P(\mathrm{obs})$ & $\triangle P^{\circ}$ & $\log _{10} P_{\mathrm{D}} / P_{\mathrm{H}}$ & $T \log _{10} P_{\mathrm{D}} / P_{\mathrm{H}}$ & $1 / T$ \\
\hline \multicolumn{6}{|c|}{ Solid range-Series I } \\
\hline $\begin{array}{l}11.70 \\
11.93 \\
27.06 \\
45.74 \\
62.64 \\
76.41 \\
4.66 \\
10.06 \\
22.45 \\
40.56 \\
59.76 \\
13.25 \\
33.40 \\
49.99 \\
80.35\end{array}$ & $\begin{array}{r}+0.032 \\
+.057 \\
+.323 \\
+.753 \\
+1.170 \\
+1.518 \\
+.006 \\
+.051 \\
+.253 \\
+.651 \\
+1.099 \\
+.107 \\
+.487 \\
+.861 \\
+1.394\end{array}$ & $\begin{array}{r}+0.102 \\
+.128 \\
+.478 \\
+1.003 \\
+1.510 \\
+1.940 \\
+.036 \\
+.112 \\
+.382 \\
+.873 \\
+1.425 \\
+.186 \\
+.674 \\
+1.134 \\
+1.789\end{array}$ & $\begin{array}{r}+0.00378 \\
+.00463 \\
+.00760 \\
+.00941 \\
+.01034 \\
+.01088 \\
+.00334 \\
+.00481 \\
+.00733 \\
+.00923 \\
+.01024 \\
+.00606 \\
+.00867 \\
+.00973 \\
+.00957\end{array}$ & $\begin{array}{r}+0.297 \\
+.364 \\
+.632 \\
+.813 \\
+.914 \\
+.976 \\
+.247 \\
+.374 \\
+.602 \\
+.790 \\
+.902 \\
+.480 \\
+.732 \\
+.846 \\
+.862\end{array}$ & $\begin{array}{r}0.012742 \\
.012725 \\
.012025 \\
.011579 \\
.011313 \\
.011145 \\
.013534 \\
.012872 \\
.012184 \\
.011681 \\
.011353 \\
.012635 \\
.011846 \\
.011504 \\
.011104\end{array}$ \\
\hline \multicolumn{6}{|c|}{ Solid range-Series II } \\
\hline $\begin{array}{r}2.54 \\
4.97 \\
11.85 \\
22.80 \\
39.00 \\
52.33 \\
52.57 \\
75.46 \\
5.36 \\
11.52 \\
23.89 \\
41.41 \\
77.69\end{array}$ & $\begin{array}{r}-0.012 \\
-.006 \\
+.075 \\
+.262 \\
+.603 \\
+.881 \\
+.919 \\
+1.497 \\
-.010 \\
+.074 \\
+.295 \\
+.657 \\
+1.568\end{array}$ & $\begin{array}{r}-0.002 \\
+.026 \\
+.146 \\
+.393 \\
+.816 \\
+1.166 \\
+1.204 \\
+1.912 \\
+.024 \\
+.143 \\
+.433 \\
+.883 \\
+1.998\end{array}$ & $\begin{array}{r}-0.0003 \\
+.0022 \\
+.00531 \\
+.00742 \\
+.00899 \\
+.00957 \\
+.00983 \\
+.01086 \\
+.00191 \\
+.00535 \\
+.00780 \\
+.00915 \\
+.01103\end{array}$ & $\begin{array}{r}-0.021 \\
+.163 \\
+.417 \\
+.610 \\
+.767 \\
+.835 \\
+.858 \\
+.973 \\
+.142 \\
+.419 \\
+.643 \\
+.784 \\
+.991\end{array}$ & $\begin{array}{r}0.014059 \\
.013478 \\
.012731 \\
.012171 \\
.011714 \\
.011465 \\
.011461 \\
.011156 \\
.013413 \\
.012755 \\
.012131 \\
.011664 \\
.011131\end{array}$ \\
\hline \multicolumn{6}{|c|}{ Liquid range-Series I } \\
\hline $\begin{array}{r}114.53 \\
99.52 \\
148.11 \\
212.25 \\
300.87 \\
409.34 \\
554.25 \\
768.66 \\
765.31 \\
135.81 \\
240.51 \\
378.50 \\
642.16 \\
88.73 \\
134.57 \\
223.83 \\
293.74\end{array}$ & $\begin{array}{r}+1.328 \\
1.037 \\
2.021 \\
3.459 \\
5.630 \\
8.466 \\
12.448 \\
18.612 \\
18.479 \\
1.763 \\
4.133 \\
7.639 \\
14.926 \\
.833 \\
1.735 \\
3.735 \\
5.447\end{array}$ & $\begin{array}{r}+1.81 \\
1.45 \\
2.68 \\
4.58 \\
7.08 \\
10.52 \\
15.28 \\
22.65 \\
22.50 \\
2.36 \\
5.28 \\
9.51 \\
18.31 \\
1.19 \\
2.33 \\
4.79 \\
6.87\end{array}$ & $\begin{array}{r}+0.00681 \\
.00628 \\
.00778 \\
.00926 \\
.01009 \\
.01102 \\
.01181 \\
.01266 \\
.01259 \\
.00748 \\
.00943 \\
.01078 \\
.01221 \\
.00578 \\
.00746 \\
.00921 \\
.01003\end{array}$ & $\begin{array}{r}+0.632 \\
.576 \\
.739 \\
.909 \\
1.024 \\
1.153 \\
1.275 \\
1.415 \\
1.407 \\
.705 \\
.937 \\
1.119 \\
1.339 \\
.525 \\
.702 \\
.909 \\
1.016\end{array}$ & $\begin{array}{r}0.010775 \\
.010909 \\
.010530 \\
.010187 \\
.009852 \\
.009555 \\
.009262 \\
.008944 \\
.008948 \\
.010613 \\
.010067 \\
.009631 \\
.009119 \\
.011018 \\
.010622 \\
.010136 \\
.009875\end{array}$ \\
\hline \multicolumn{6}{|c|}{ Liquid range-Series II } \\
\hline $\begin{array}{r}104.60 \\
172.94 \\
283.76 \\
462.63 \\
672.21 \\
782.22 \\
92.60 \\
159.09 \\
288.00 \\
504.27 \\
741.41 \\
94.19 \\
81.63 \\
90.02 \\
157.68 \\
90.67 \\
186.04 \\
380.32 \\
771.21\end{array}$ & $\begin{array}{r}1.157 \\
2.573 \\
5.202 \\
9.888 \\
15.761 \\
18.939 \\
.923 \\
2.263 \\
5.309 \\
11.029 \\
17.748 \\
.941 \\
1.314 \\
.935 \\
2.223 \\
.893 \\
2.863 \\
7.673 \\
18.562\end{array}$ & $\begin{array}{r}1.59 \\
3.36 \\
6.58 \\
12.23 \\
19.27 \\
23.04 \\
1.30 \\
2.98 \\
6.70 \\
13.58 \\
21.66 \\
1.32 \\
1.64 \\
1.30 \\
2.93 \\
1.26 \\
3.72 \\
9.55 \\
22.60\end{array}$ & $\begin{array}{r}0.00655 \\
.00835 \\
.00995 \\
.01134 \\
.01228 \\
.01260 \\
.00605 \\
.00806 \\
.00999 \\
.01154 \\
.01250 \\
.00604 \\
.00864 \\
.00622 \\
.00799 \\
.00603 \\
.00860 \\
.01077 \\
.01254\end{array}$ & $\begin{array}{r}0.603 \\
.804 \\
1.004 \\
1.202 \\
1.353 \\
1.411 \\
.551 \\
.770 \\
1.010 \\
1.234 \\
1.392 \\
.551 \\
.779 \\
.565 \\
.763 \\
.548 \\
.834 \\
1.119 \\
1.403\end{array}$ & $\begin{array}{r}0.010852 \\
.010383 \\
.009908 \\
.009437 \\
.009075 \\
.008927 \\
.010977 \\
.010462 \\
.009893 \\
.009354 \\
.008979 \\
.010961 \\
.011097 \\
.011004 \\
.010471 \\
.010998 \\
.010313 \\
.009626 \\
.008941\end{array}$ \\
\hline
\end{tabular}

a perceptibly better fit, and as it involves an additional constant was abandoned in favor of the two constant eq (4).

$$
T \log _{10} P_{\mathbf{D}} / P_{\mathbf{H}}=A-B / T .
$$

In the solid range the scatter of the points did not permit a satisfactory choice between the $\log _{10} P_{\mathbf{D}} / P_{\mathrm{H}}$ plot or the $T \log _{10} P_{\mathbf{D}} / P_{\mathrm{H}}$ against $1 / T$; but the latter 


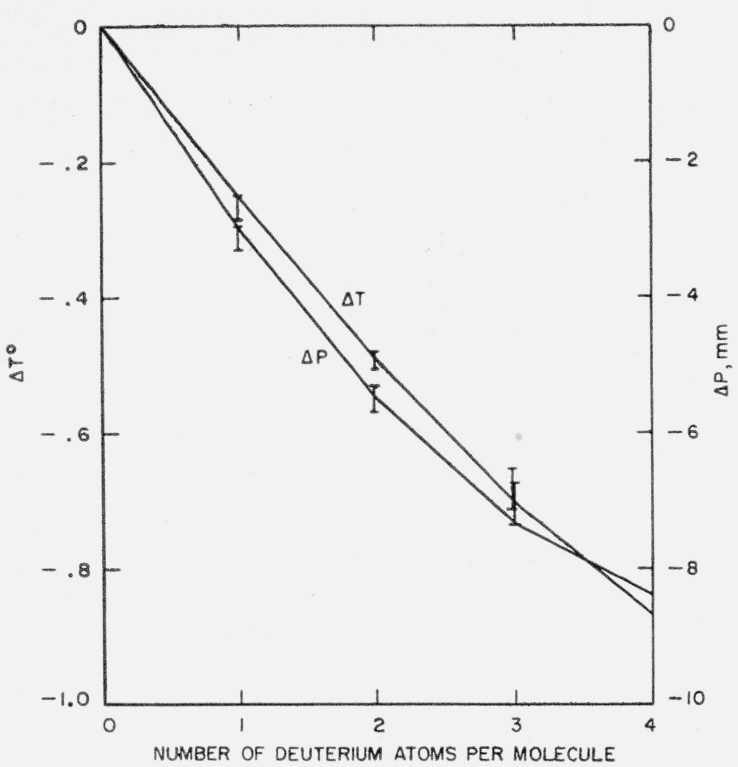

Figure 6. Triple points of the deuteromethanes.

was chosen in harmony with the choice for the liquid range.

One fixed point was used in establishing the equation for the solid state vapor pressure data. This point was determined in such a way as to make the discontinuity between the liquid and solid state equations for $T \log _{10} P_{\mathrm{D}} / P_{\mathrm{H}}$ consistent with the vapor pressure equations for solid and liquid $\mathrm{CH}_{4}$. This was done by extrapolating eq (2) for liquid $\mathrm{CH}_{4}$ to the triple point of the deuteromethane and calculating at this point $\log _{10} P_{\mathrm{H}}$ (liquid) from eq (2) and $\log _{10} P_{\mathrm{H}}$ (solid) from equation (1b). The term $T\left[\log _{10} P_{\mathrm{H}}\right.$ (liquid) $-\log _{10} P_{\mathrm{H}}$ (solid)] was used to represent the discontinuity at the triple point of the deuteromethane. It was added to the value of $T \log _{10} P_{\mathrm{D}} / P_{\mathrm{H}}$ (liquid) at that temperature to give the value of $T \log _{10} P_{\mathrm{D}} / P_{\mathrm{H}}$ (solid) at the same temperature, and this value was used to define the limit of the solid state equation. It may be noted at this point that the revision of the denominator constant of the Antoine equation for solid $\mathrm{CH}_{4}$ has a significant effect in this calculation, as shown in the following tabulation

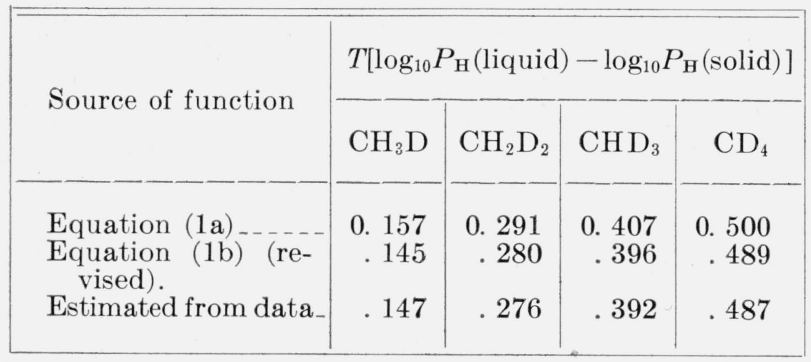

In every case the revised equation gives a value for the discontinuity that is more nearly consistent with the experimental points than does the unrevised equation.
Table 10 gives a complete list of the constants for eq (4) fitting the data calculated on the basis of the various analyses. In the last column $\epsilon$ represents the mean deviation in millimeters of mercury of the data from the equations. The deviations were calculated for equations resulting from analysis 1 . With the exception of the $\mathrm{CD}_{4}$, they should be approximately the same for the other analyses. The mean deviation, $\pm 0.027 \mathrm{~mm}$, of the $\mathrm{CD}_{4}$ data shown for analysis 1 is the deviation of the data of all the $\mathrm{CD}_{4}$ samples from the equation fitted to the average of all. However, much of this represents systematic differences between the samples, as sample 1 data lie consistently below the sample 2 data. In the final treatment of the data based on analysis 5 the equation was derived to fit only the data from sample 1. For this sample the mean deviation was $0.009 \mathrm{~mm}$. The constants listed in table 10 show clearly the differences resulting from the different compositions attributed to the samples.

TABLE 10. Constants for the equation $T \log _{10} P_{\mathrm{D}} / P_{\mathrm{B}}=A-B / T$

\begin{tabular}{|c|c|c|c|c|c|c|}
\hline \multirow{2}{*}{ Analysis } & \multirow{2}{*}{ Methane } & \multicolumn{2}{|c|}{ Solid range } & \multicolumn{2}{|c|}{ Liquid range } & \multirow{2}{*}{$\epsilon(\mathrm{mm})$} \\
\hline & & $A_{\mathrm{s}}$ & $B_{\mathrm{s}}$ & $A_{\mathrm{L}}$ & $B_{\mathrm{L}}$ & \\
\hline $1 \ldots$ & $\begin{array}{l}\mathrm{CH}_{3} \mathrm{D} \\
\mathrm{CH}_{2} \mathrm{D}_{2} \\
\mathrm{CHD}_{3} \\
\mathrm{CD}_{4} \text { (all) }\end{array}$ & $\begin{array}{l}1.424 \\
2.842 \\
4.152 \\
5.135\end{array}$ & $\begin{array}{l}124.7 \\
234.2 \\
329.3 \\
374.8\end{array}$ & $\begin{array}{l}\text { 1. } 481 \\
\text { 2. } 781 \\
\text { 3. } 773 \\
\text { 5. } 136\end{array}$ & $\begin{array}{l}144.5 \\
254.6 \\
328.5 \\
419.1\end{array}$ & $\begin{array}{r} \pm 0.015 \\
\pm .017 \\
\pm .018 \\
\pm .027\end{array}$ \\
\hline 2 & $\begin{array}{l}\mathrm{CH}_{3} \mathrm{D} \\
\mathrm{CH}_{2} \mathrm{D}_{2} \\
\mathrm{CHD}_{3} \\
\mathrm{CD}_{4}\end{array}$ & - & - & - & ... & - \\
\hline 3 & $\begin{array}{l}\mathrm{CH}_{3} \mathrm{D} \\
\mathrm{CH}_{2} \mathrm{D}_{2} \\
\mathrm{CHD}_{3} \\
\mathrm{CD}_{4} \text { (all) }\end{array}$ & - & W... & $\begin{array}{l}\text { 1. } 324 \\
\text { 2. } 632 \\
\text { 3. } 942 \\
\text { 5. } 206\end{array}$ & $\begin{array}{l}129.2 \\
242.6 \\
343.4 \\
425.1\end{array}$ & - \\
\hline 4. & $\begin{array}{l}\mathrm{CH}_{3} \mathrm{D} \\
\mathrm{CH}_{2} \mathrm{D}_{2} \\
\mathrm{CHD}_{3} \\
\mathrm{CD}_{4} \text { (all) } \\
\mathrm{CD} \mathrm{D}_{4}(1)\end{array}$ & $\begin{array}{l}\text { 1. } 259 \\
2.390 \\
4.576 \\
4.915 \\
5.357\end{array}$ & $\begin{array}{l}110.2 \\
195.7 \\
361.7 \\
355.3 \\
396\end{array}$ & $\begin{array}{l}\text { 1. } 3275 \\
2.742 \\
4.101 \\
5.138 \\
-.-.-\end{array}$ & $\begin{array}{l}129.5 \\
253.5 \\
355 \\
419 \\
-. .-\end{array}$ & - \\
\hline $5 \ldots$ & $\begin{array}{l}\mathrm{CH}_{3} \mathrm{D} \\
\mathrm{CH}_{2} \mathrm{D}_{2} \\
\mathrm{CHD}_{3} \\
\mathrm{CD}_{4}(1)\end{array}$ & $\begin{array}{l}\text { 1. } 260 \\
\text { 2. } 694 \\
\text { 4. } 452 \\
\text { 5. } 529\end{array}$ & $\begin{array}{l}110.2 \\
222.2 \\
351.7 \\
410.5\end{array}$ & $\begin{array}{l}1.328 \\
2.671 \\
3.969 \\
5.159\end{array}$ & $\begin{array}{l}129.5 \\
245.4 \\
343.8 \\
421.1\end{array}$ & 土.009 \\
\hline
\end{tabular}

A further check on the internal consistency of the data was made in the following way. Using the triple point pressures and temperatures of the four deuteromethanes shown in table 7 , the function $T \log _{10} P_{\mathrm{D}} /$ $P_{\mathrm{H}}$ for the solid at this pressure was calculated and compared with the value taken as a fixed point in the derivation of the solid deuteromethane equations. The values found are compared below.

\begin{tabular}{|c|c|c|}
\hline \multirow{2}{*}{ Sample } & \multicolumn{2}{|c|}{$T \log _{10} P_{\mathrm{D}} / P_{\mathrm{H}}$} \\
\cline { 2 - 3 } & $\begin{array}{c}\text { From triple } \\
\text { point data }\end{array}$ & $\begin{array}{c}\text { From equation } \\
\text { for solid } \\
\text { deuteromethane }\end{array}$ \\
\hline & -1.95 & 0.958 \\
$\mathrm{CD}_{4}$ & .54 & .543 \\
$\mathrm{CH}_{3}$ & .24 & .230 \\
$\mathrm{CH}_{2} \mathrm{D}_{2}$ & .04 & .041 \\
$\mathrm{CH}_{3} \mathrm{D}_{\ldots}$ & & \\
\hline
\end{tabular}


The agreement is good. Only in the case of $\mathrm{CH}_{3} \mathrm{D}$ is an appreciable error observable. If the triple point of $\mathrm{CH}_{3} \mathrm{D}$ were $84.45 \mathrm{~mm}$ instead of $84.52 \mathrm{~mm}$ the values for $T \log _{10} P_{\mathrm{D}} / P_{\mathrm{H}}$ would be in agreement. This difference in triple point pressure could be accounted for in either of two ways, (1) there may be a 2 percent impurity of $\mathrm{CH}_{4}$ in the $\mathrm{CH}_{3} \mathrm{D}$ sample, which is not an unlikely possibility, or (2) an error of $0.07 \mathrm{~mm}$ was made in reading the triple point pressure.

\subsection{Discussion of the Vapor Pressure}

The vapor pressure ratios $P_{\mathrm{D}} / P_{\mathrm{H}}$ show certain regularities of behavior which are worthy of mention. The substitution of each successive protium atom by a deuterium atom causes a nearly constant change in the constants $A$ and $B$. A slight but consistent deviation from a linear increase of $A$ and $B$ occurs as may be seen by reference to figure 7 . It has been postulated as a working approximation in estimating the vapor pressure of the middle member of a series of increasingly deuterium substituted compounds, such as the waters, that the vapor pressure of the middle member (HDO) is a geometric mean of the vapor pressures of the extreme members $\left(\mathrm{H}_{2} \mathrm{O}\right.$ and $\mathrm{D}_{2} \mathrm{O}$ ). Within the limits of experimental error the few determinations on HDO support this hypothesis, and a theoretical justification has been presented [42]. In the case of the methanes a similar hypothesis would require that the ratios $P_{\mathrm{D}} / P_{\mathrm{H}}$ should form a geometric progression. This would require $A$ and $B$ to form a linear series. The nonlinearity of the constant $A$ indicates that deviations from a geometric progression do exist though they are small. The deviations from a geometric progression are also evident in the fact that the ratios $P_{\mathrm{D}} / P_{\mathrm{H}}$ are not unity at exactly the same temperatures; but the temperatures at which this ratio is unity are successively lower the more highly deuterium substituted is the methane. The melting points also form a nearly linear series as may be seen in figure 6 . The deviation from linearity appears to be real, though slight.

Because of the form of the equations representing the vapor pressure ratios, it appears that from the temperatures at which measurements were carried out up to the critical point the vapor pressure of the deuterium compound will always be greater. If the same form of vapor pressure relation is applicable throughout the liquid range then it appears that the vapor pressure ratios will have maxima at or below the critical points. The maximum vapor pressure ratios indicated by the equations range from 1.009 in the case of $\mathrm{CH}_{3} \mathrm{D}-\mathrm{CH}_{4}$ to 1.037 in the case of $\mathrm{CD}_{4}-\mathrm{CH}_{4}$.

\subsection{Ideality of the Solutions of Isotopic Isomers of Methane}

In view of the complexity of the two mixtures which were used as $\mathrm{CD}_{4}$ samples in the work of Brickwedde and Scott, and the difficulty of obtaining an accurate

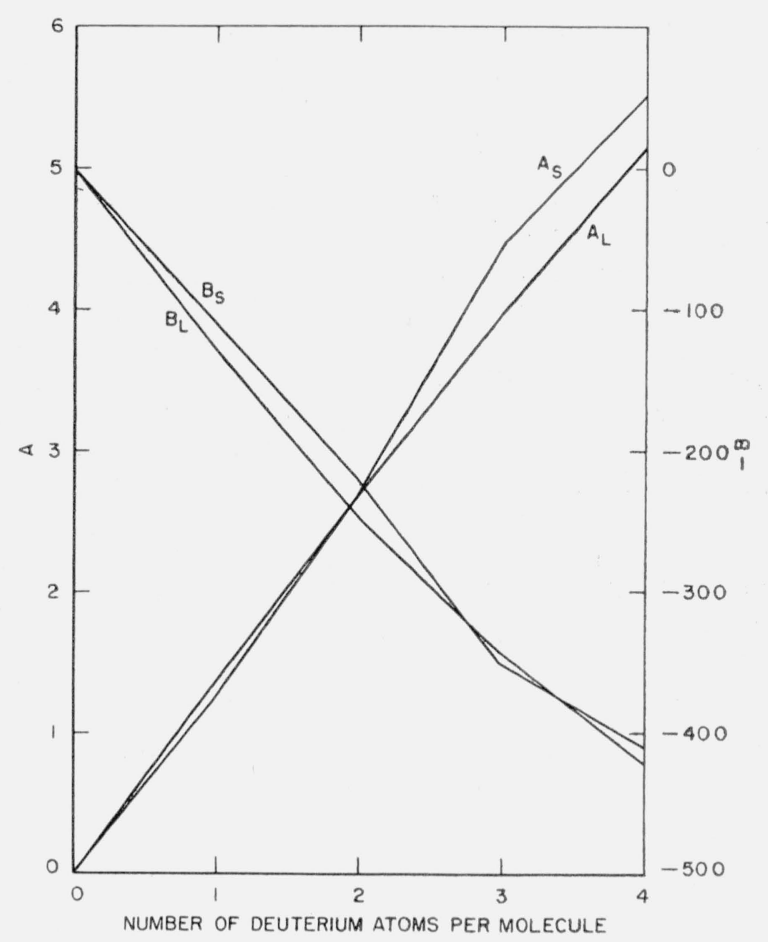

Figure 7. Constants of the equations $T \log _{10} P_{\mathrm{D}} / P_{\mathrm{H}}=A-B / T$.

analysis, it appears that only the roughest estimates can be made of the magnitude of deviations from ideality which they exhibit. Two estimates have been made.

One estimate has been made of the deviations from ideality to be expected if the deuteromethanes form regular solutions, according to Hildebrand's criterion, that is, have ideal entropy of mixing. For this type of solution the activity of a component 1 is given by eq (7).

$$
\begin{aligned}
& R T \log _{e} a_{1}=R T \log _{e} X_{1}+V_{1} \phi_{2}^{2}\left[\left(\Delta H_{1} / V_{1}\right)^{1 / 2}-\right. \\
& \left.\left(\Delta H_{2} / V_{2}\right)^{1 / 2}\right]
\end{aligned}
$$

where $\Delta H / V$ is the latent heat of vaporization per cubic centimeter, $\phi$ is the volume fraction and $V$ the molar volume of a pure component. Using the following experimental values the activity coefficient of $\mathrm{CH}_{3} \mathrm{D}$ in its 10 percent solution in $\mathrm{CH}_{4}$ was calculated to be 1.000058 . This calculation places the possibility of finding deviations from ideality of this

\begin{tabular}{|c|c|c|}
\hline Sample & $\Delta H[21]$ & $V[22]$ \\
\hline $\begin{array}{l}\mathrm{CH}_{4}-- \\
\mathrm{CH}_{3} \mathrm{D}_{-}\end{array}$ & $\begin{array}{c}c a l \\
2,036 \\
2,050\end{array}$ & $\begin{array}{l}\mathrm{cm}^{3} \\
33.63 \\
32.4\end{array}$ \\
\hline
\end{tabular}
type beyond experimental precision.

Another extremely rough estimate of the deviations from ideality in the solutions rich in $\mathrm{CD}_{4}$ has been made by comparison of the vapor pressure of $\mathrm{CD}_{4}$ 
calculated from samples 1 and 2-4. It will be noted that sample 2-4 gives values always higher than sample 1. This suggests that sample 2, which contained more admixed $\mathrm{CHD}_{3}$ had a vapor pressure higher than it would have had if the solution were ideal. If we consider the vapor pressure of pure $\mathrm{CD}_{4}$ to be that calculated from the purer sample 1 , then $\gamma$, the activity coefficient of $\mathrm{CD}_{4}$ in sample 2 , is given by $P_{\mathrm{CD}_{4}}$ (sample $2-4$ calculation $)=\gamma P_{\mathrm{CD}_{4}}$ (sample 1 calculation). The value of $\gamma$ thus calculated averages about 1.00028 in the liquid range, and does not vary much with temperature. In the solid range it increases from 1.0008 near the triple point to 1.0035 at $77^{\circ}$. These values appear to represent the activity coefficient of $\mathrm{CD}_{4}$ in a solution of about 70 percent $\mathrm{CD}_{4}$ as compared with its activity coefficient in a solution of about 92 percent $\mathrm{CD}_{4}$, the assumption being made that the vapor pressure measurements are not systematically wrong for either of these samples.

The relative volatilities of the deuteromethanes with respect to $\mathrm{CH}_{4}$ have been calculated at the normal boiling point of $\mathrm{CH}_{4}$; they are: $\mathrm{CH}_{3} \mathrm{D}, 1.0035$; $\mathrm{CH}_{2} \mathrm{D}_{2}, 1.010 ; \mathrm{CHD}_{3}, 1.019 ; \mathrm{CD}_{4}, 1.029$.

\section{References}

[1] S. F. Pickering, J. Phys. Chem. 28, 97 (1924).

[2] R. L. Copson and P. K. Frohlich, Ind. Eng. Chem. 21, 1116 (1929).

[3] D. R. Stull, Ind. Eng. Chem. 39, 517 (1947).

[4] International Critical Tables III, 208, 216, 228 (McGrawHill Book Co., New York, N. Y., 1928).

[5] G. Egloff, Physical Constants of Hydrocarbons I, 26 (Reinhold Publishing Corp., New York, N. Y., 1939).

[6] J. Timmermans, Physico Chemical Constants of Pure Organic Compounds, Elsevier (1950).

[7] F. D. Rossini, K. S. Pitzer, and others, Selected values of properties of hydrocarbons, NBS Circular 461, p. 121 (1947).

[8] M. A. Hunter, J. Phys. Chem. 10, 330 (1906).

[9] F. Henning and A. Stock, Z. Physik 4, 226 (1921).

[10] E. Karwat, Z. physik. Chem. 112, 488 (1924).

[11] F. A. Freeth and T. T. H. Verschoyle, Proc. Roy. Soc. A130, 453 (1931).

[12] A. W. Tichner and F. P. Lossing, J. Phys. and Colloid Chem. 55, 733 (1951).
[13] K. Olszewski, Compt. rend. 100, 940 (1885).

[14] C. A. Crommelin, Commun. Leiden, 131b (1912).

[15] A. Eucken and E. Karwat, Z. physik. Chem. 112, 467 (1924).

[16] K. Clusius, Z. physik. Chem. B3, 41 (1929).

[17] R. Wiebe and M. J. Brevoort, J. Am. Chem. Soc. 52, 622 (1930).

[18] W. Fischer and W. Klemm, Z. physik. Chem. 147A, 275 (1935).

[19] A. Kruis, L. Popp, and K. Clusius, Z. Elecktrochem. 43, 664 (1937).

[20] K. Clusius, L. Popp, and A. Frank, Physica 4, 1105 (1937).

[22] K. Clusius and K. Wiegand, Z. physik. Chem. B46, 1 (1940).

[23] L. A. K. Stavely and A. K. Gupta, Trans. Faraday Soc. 45, 50 (1949).

[24] A. Stock, F. Henning, and E. Kuss, Ber. 54B, 1119 (1921).

[25] Handbuch der Experimental Physik VIII 2, 527 Akademische Verlagsgesellschaft (1929).

[26] F. G. Keyes, R. S. Taylor, and L. B. Smith, J. Math. Phys. M. I. T. 1, 211 (1922).

[27] C. S. Cragoe (NBS unpublished report, 1919).

[28] S. Wroblewski, Compt. rend. 99, 136 (1884).

[29] E. Cardoso, J. chim. phys. 13, 312 (1915).

[30] A. Eucken and W. Berger, Z. ges. Kälte-Ind. 41, 145 (1934).

[31] L. M. Volova, J. Phys. Chem. (U. S. S. R.) 14, 268 (1940).

[32] O. T. Bloomer and J. D. Parent, Inst. Gas Technol., Bull. 17 (1952).

[33] F. G. Keves, B. Townshend, and L. H. Young, J. Math. Phys., M. I. T. 1, 243 (1922).

[34] J. Dewar, Phil. Mag. 18, 210 (1884).

[35] K. Bennewitz and N. Andreev, Z. physik. Chem. A142, 37 (1929).

[36] G. T. Armstrong, F. G. Brickwedde, and R. B. Scott, J. Chem. Phys. 21, 1297 (1953).

[37] D. F. Stedman, Can. J. Research 13B, 114 (1935).

[38] K. Clusius and L. Popp, Z. physik. Chem. B46, 63 (1940).

[39] H. J. Hoge and F. G. Brickwedde, J. Research NBS 22, 351 (1939) RP 1188.

[40] F. L. Mohler and V. H. Dibeler, J. Research NBS 45, 441 (1950) RP 2155.

[41] D. O. Schissler, S. O. Thompson, and J. Turkevich, AECU 1387 (Sept. 28, 1951).

[42] B. Topley and H. Eyring, J. Chem. Phys. 2, 217 (1934).

Washington, December 17, 1954. 